Article

\title{
Advances in Solar Energy towards Efficient and Sustainable Energy
}

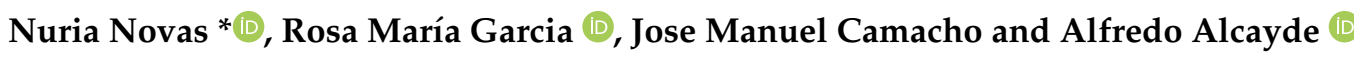 \\ Department of Engineering, University of Almeria, ceiA3, 04120 Almeria, Spain; rgarciasalvador@ual.es (R.M.G.); \\ jcs066@ual.es (J.M.C.); aalcayde@ual.es (A.A.) \\ * Correspondence: nnovas@ual.es; Tel.: +34-950015686
}

Citation: Novas, N.; Garcia, R.M.; Camacho, J.M.; Alcayde, A. Advances in Solar Energy towards Efficient and Sustainable Energy. Sustainability 2021, 13, 6295. https://doi.org/ $10.3390 /$ su13116295

Academic Editor: Marc A. Rosen

Received: 19 March 2021

Accepted: 26 May 2021

Published: 2 June 2021

Publisher's Note: MDPI stays neutral with regard to jurisdictional claims in published maps and institutional affiliations.

Copyright: (C) 2021 by the authors. Licensee MDPI, Basel, Switzerland. This article is an open access article distributed under the terms and conditions of the Creative Commons Attribution (CC BY) license (https:// creativecommons.org/licenses/by/ $4.0 /)$.

\begin{abstract}
Conventional energy resources are not climate sustainable. Currently, engineers and scientists are looking for sustainable energy solutions influenced by climate change. A wide variety of sustainable natural energy resources are available, but they require technical solutions for their implementation. The general trend in energy research is based on renewable resources, amongst which solar energy stands out, being the most mature and widely accepted. In this paper, the current state of the sustainable energy system has been analysed. The main purpose is to provide additional context to assess future scenarios. The study of past contributions allows sustainability planning and increasing the welfare of future society. The aim is to highlight global trends in research on sustainable solar energy from 1995 to 2020 through a bibliometric analysis of 4260 publications. According to their linkages, the analysed articles are distributed in nine clusters: Sustainability assessment, Sustainable energy solutions, Environmental payback time analysis, Sustainability of solar energy in different scenarios, Environmental sustainability, Solar energy applications, Sustainable energy optimisation, Energy transition and Energy and sustainable scenarios. The most repeated keywords are Sustainability, Renewable energy, and Solar energy. Energy research and the exploration of new renewable solar resources are still necessary to meet sustainable energy's future challenges.
\end{abstract}

Keywords: sustainability; solar energy; renewable energy

\section{Introduction}

Energy sustainability is extensively discussed in the scientific and political community. Until now, there have been two different approaches on the matter. One considers an increase in electricity consumption essential for the economic development and social progress of the countries, whereas others are more concerned about keeping carbon consumption within certain limits. The definition of sustainability is not unanimous among the scientific community. In the literature, it is associated with different concepts depending on the point of view studied.

In planning energy-sustainable development, sustainability indicators must be considered to compare their implementation. To do this, the emergy concept is identified and used in numerous works. Emergy involves indicators such as the Environmental Load Ratio (ELR), Emergy Yield Ratio (EYR) and Emergy Sustainability Index (ESI), defined as the ratio between EYR and ELR, the Renewable Percentage (RP), Environmental Load Ratio, Emergy Investment Ratio (EIR) and others. The scientific community is not unanimous in establishing single energy sustainability indicators. Another indicator is the Energy Payback Time (EPBT), which allows assessing the time necessary to produce the amount of energy that compensates the investment. Another one is the greenhouse gas (GHG) emission rate. This indicator has an environmental character, and it allows the evaluation of the emission rate divided by the amount of electricity generated in the life cycle of a process [1].

In the literature, there is a wide variety of applications oriented towards sustainable energy solutions. The water supply for human consumption is just an example. Energy, 
environmental, technical, social, and economic feasibility studies are required to reduce the freshwater shortage. The areas most affected by freshwater scarcity are the areas with the highest solar radiation. Solar energy can be appropriate, environmentally, and economically sustainable in the long term [2]. Another example of commercial-agricultural applicability is solar greenhouses [3].

The method developed in this work applies bibliometric techniques based on the use of databases, allowing the distribution of contributions in different communities. Each community focuses on diverse topics within the main theme of the study. This distribution is carried out without establishing a bias by citations or years of publication; the main criteria is the effective relationship between the authors and the keywords they present. Thus, advances in the field of sustainability and energy are studied, eliminating papers and authors not directly related to this field, and focusing on the most relevant papers. The method is a variant of the one described in [4]. The differences with this one are described in Section 2 of the paper. Thus, the progress in the field of sustainability and energy is studied, eliminating works and authors not directly related to this field, and focusing on the most relevant works.

In Section 3.1, a generic analysis of the papers by authors, affiliations, language of publication and documents types is established. As indicated by many scientific contributions found, research on energy sustainability is still ongoing. These publications can be found in 1146 different journals, in different categories and languages. The number of scientific contributions in this topic doubles per decade, which leads to a considerable number of papers distributed within the same area of research.

In Section 3.2, a review of the most important works of these communities is carried out, verifying that they focus on the topic of study, through the search for the initial keywords. The application of the methodology allows us to know the effective progress in the area, since the analysis is focused exclusively on the works that, in addition to meeting the search criteria, meet the conditions imposed by the method, which, in a very summarized form, seeks that these works be cited by the works that meet the same search conditions, that is, it is considered important in the area of knowledge if it is cited by colleagues in your area, and not by those in other areas, even if a priori they are related.

In Section 4 the most relevant conclusions of the results (Section 3) are shown.

There is an active collaboration between authors from different thematic communities. This paper has established the different communities that have been consolidated over time in energy sustainability research.

\section{Materials and Methods}

This work studies scientific world publications based on solar energy advances, oriented towards efficiency and sustainability, which are indexed in the Scopus database. This database is the one with the greatest number of publications worldwide [5]. The search engine used to automatically obtain bibliographic data was a rasNetBot API interface, developed at the University of Almería, by a research group from the Department of Engineering in recent years. The method described in [4] has been used, improving the data mining and analysis part, as shown if the flow chart in Figure 1.

The designed software is divided into four modules: search module ("GET ALL PAPERS"), where the search is performed according to the established criteria, obtaining from Scopus the summary result of the papers that match the criteria; module 2 ("GET AUTHOR DATA", the Scopus ID of all the previous papers is selected and a search is performed for each of the authors, obtaining one file per search; module 3 ("GET COLLABORATOR NETWORK"), the same is done as in 2 but in this case for each of the papers, obtaining a file for each paper; module 4 ("DATA ANALYSIS", with data mining and analysis techniques, both papers and authors are related, obtaining among others: results of community detection, extraction of keywords by community, authors by community, data shown in the following sections of the paper. 


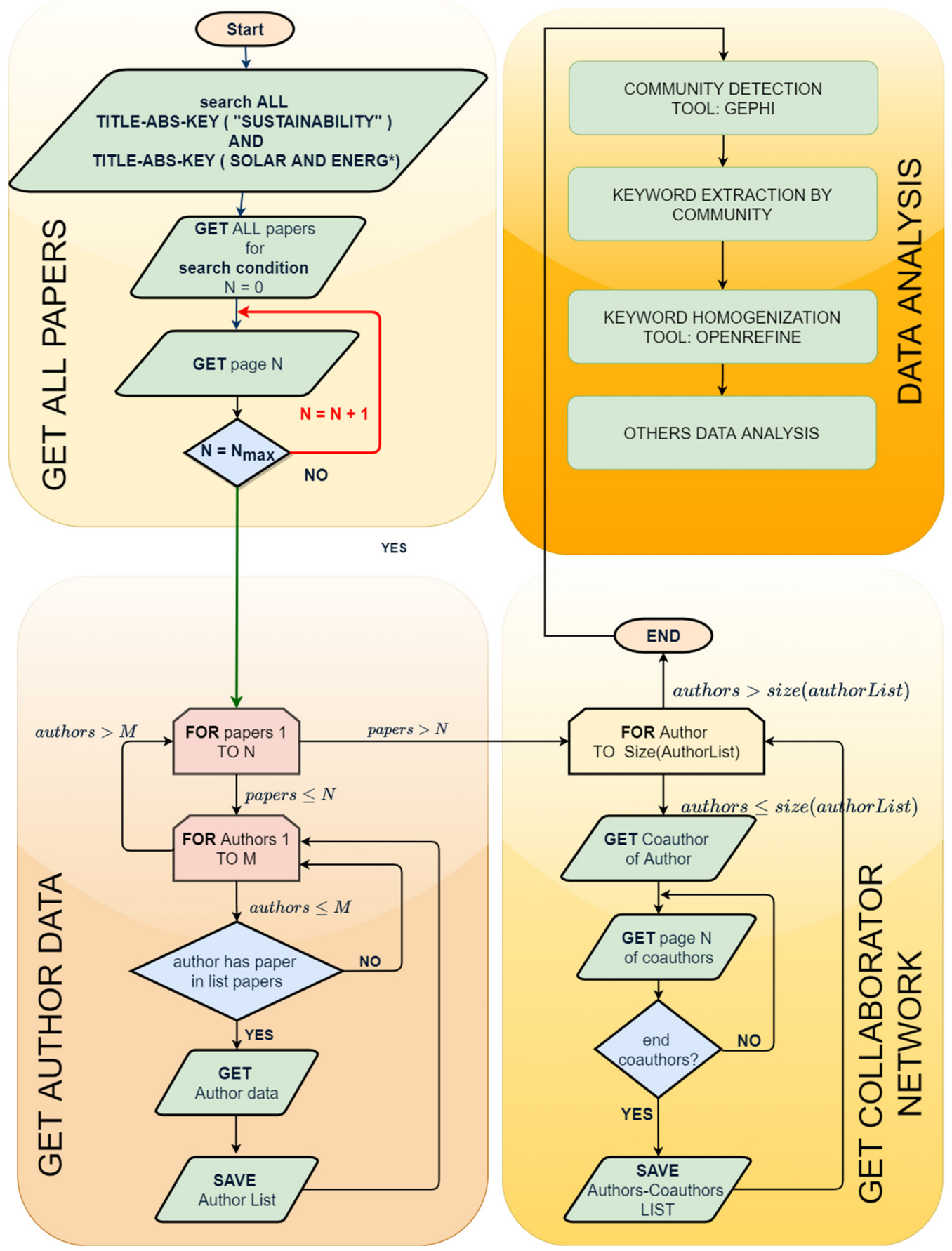

Figure 1. Flowchart of the methodology.

"Sustainability" and "Solar energy" have been used as keywords for the search process. These words can be found in fields such as the abstract, the title or the keywords of the publication. The data resulting from this search are carefully analysed using community detection algorithms, establishing the size of the nodes or publications. This size is proportional to its $\mathrm{H}$ index, the relationship between nodes indicates the collaboration between the authors of the works. The "Gephi" open-source program [6] is used to represent the nodes. Through this program it is possible to establish the main research areas within the subject studied, the advances developed in recent years, as well as the collaboration structures involved in the process, being able to develop a global vision of the subject. The analysis raises some considerations on how solar energy has been implemented throughout 
the world, what the trend is, how solar energy competes against other renewable energies and its role in environmental and socio-economic sustainability.

The method adopted is based on the analysis and use of data mining techniques. Through its application, inadequate and frequent practices in other publications can be discovered, in terms of filtering of papers, citations, etc. In this way, papers that do not present important relationships with other communities are eliminated, as well as self-cited papers.

The method also allows the elimination of groups that consider a topic of study that is not related to the purpose of this work. These subgroups are discarded in our work because they do not provide information on the subject or are not considered important in terms of relationships with other publications of our interest.

Another important aspect of the method used is the possibility of establishing considerations on the age of the articles, or the emergence of new research groups in the subject matter. This assessment is established when these works are related to others, independently of the year in which they were published. The relationship of new works with others allows them to acquire greater importance and, therefore, a greater node size in their representation. The identification of incipient communities or groups in their early phase is still complex, as this requires a meticulous analysis of the papers.

On the other hand, the number of citations of a publication is not a selection parameter, as it may not be indicative of the importance of a paper in a community. There may be papers with many citations, but only a few of them refer to papers that meet the search criteria, so they are of less importance. There may also be articles with a high number of citations that have no relation to other publications, either because they are self-citations or citations to publications that have nothing to do with the subject of the study. The criterion that marks the importance of a paper is established by the number of citations among the papers that meet the initial selection criteria.

\section{Results and Discussion}

A generic analysis of the works studied is established, starting from a general aspect to the most specific one.

\subsection{Analysis by Documents}

It is important to keep in mind that researchers are the driving force behind present and future technological development. There are 11,848 authors from 131 countries, investigating in the nine different areas studied in this paper (Section 3.2). Figure 2 shows the worldwide representation of research activity in the topics covered, with a range of colour grading according to the number of authors from the same origin. In the distribution by continents, Europe stands out with 4080 researchers (35.41\%), followed by Asia with 3472 researchers (30.14\%), America with 3027 researchers (26.27\% with $21.50 \%$ from North America), South Africa (502 researchers and 4.36\%) and finally Oceania (440 researchers and $3.82 \%$ ). Within Europe, Italy is the country that contributes the most with $6.77 \%$ of the total, the largest contribution in Asia is made by China with $8.59 \%$ and in America the greatest contribution is made by the United States. The map shows that the African continent is where there is a greater concentration of countries that do not contribute with any researcher on this subject, as happens in other publications such as $[7,8]$.

The highest concentration of authors is in 25 countries, with a contribution of more than 100 authors per country (Figure 3). In this figure, 9207 investigators have been represented, equivalent to $79.91 \%$ of the existing total. The country with the highest contribution of researchers is the United States $2107(18.29 \%)$, followed by China with 990 researchers $(8.59 \%)$, Italy with 780 researchers $(6.77 \%)$ and India with 710 researchers $(6.17 \%)$. The remaining 21 countries have a percentage contribution of less than $5 \%$. The results show that both United States and Asian countries are actively collaborating on progress by creating partnerships with other countries to move forward, as seen by the interlocking of communities. On the other hand, Europeans work among themselves, as 
is the case of Germans and Spaniards, who have established collaborations during recent years as is reflected in publications and cooperation agreements.

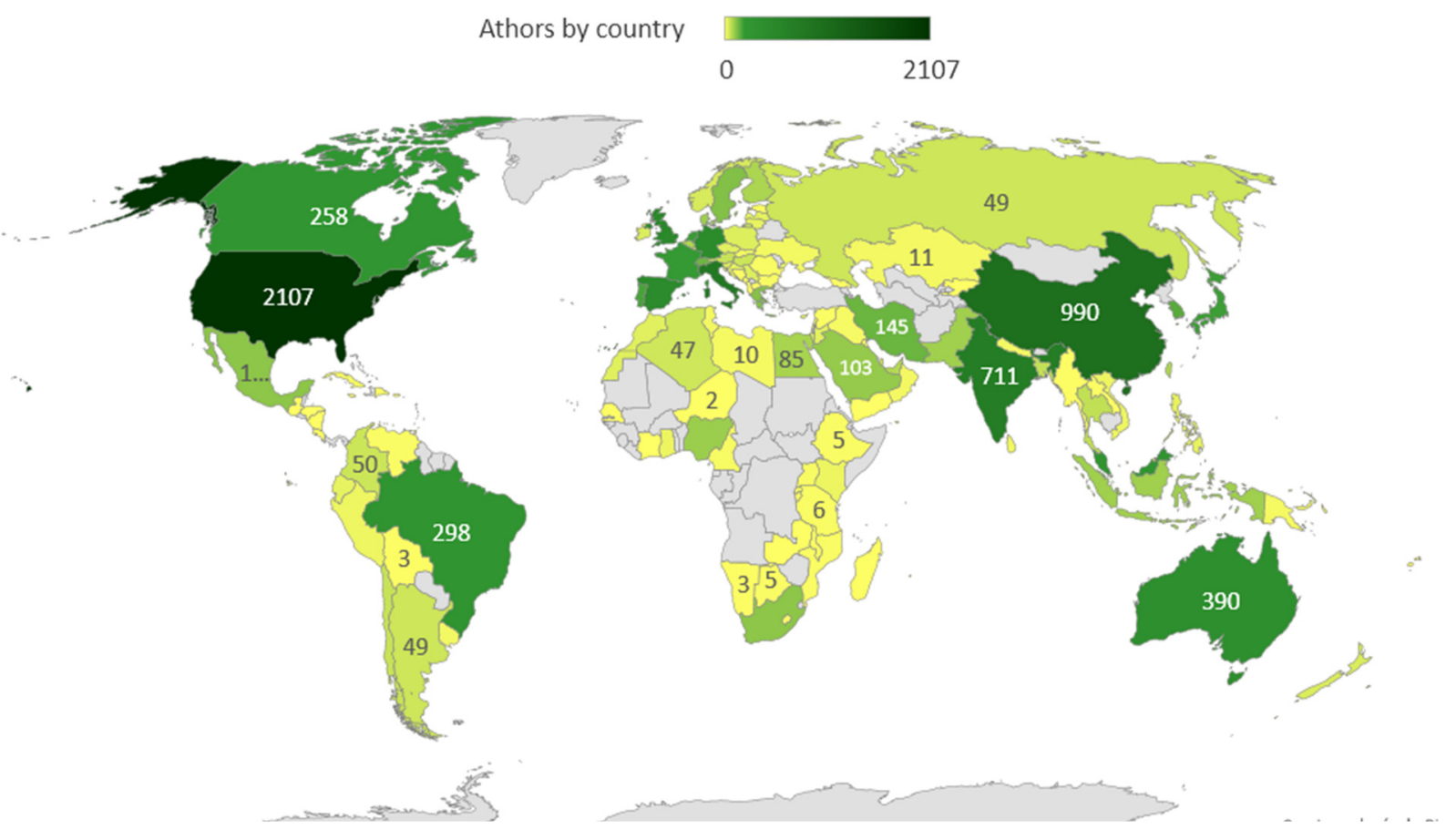

Figure 2. Author distribution by country.

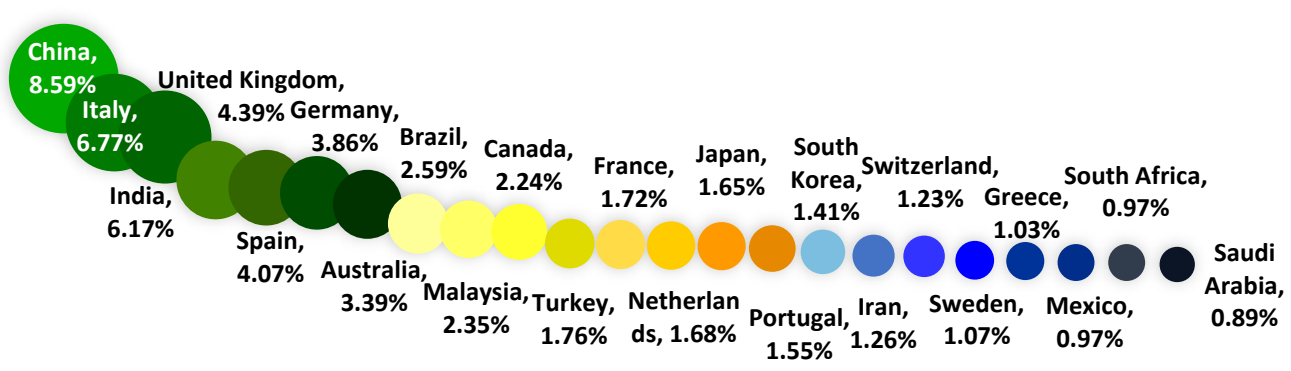

Figure 3. Author distribution by top 25 countries (79.91\% of the total).

The analysed data show that 11,785 authors are researching in the field of Solar Energy and Sustainability. Table 1 shows the list of the 20 authors with the highest H-Index according to the data recorded in Scopus. In this list, all authors have an H-Index above 100. If the authors in the top 20 are related to their countries of affiliation, we find that among the 20 countries that publish the most on this subject, only eight are represented in Table 1 . There are six authors whose origin is the country with the highest contribution in publications on this subject, the United States (30\% of top 20 authors and with 2107 publications). The representatives of the United States have $\mathrm{H}$ indices that range between 227 and 121. The second country with three representatives is Germany (15\% of top 20 authors), which occupies the seventh position in research on this subject with $3.86 \%$ of global publications (445 publications) and their representatives in this top 20 authors 
have H-Index between 167 and 128. In the third position, with 10\% of the top 20 authors with two representatives per country, are China, Australia, and Switzerland, with the global positions by publications of 2 (990 publications), 8 (390 publications) and 19 (142 publications), respectively. One of the representatives of this top 20 is from Switzerland and is the author with the highest H-Index with 256, M. Gräetzel (ID Scopus 35463345800). The remaining five countries have an author in this top 20, as is the case of the United Kingdom, that occupies the global position 5 based on 506 publications, France with position 13 with 198 publications, Japan in position 15 with 190 publishers. Denmark is in position 26 with 94 contributions and Singapore is in position 33 with 75 publications. Table 1 does not include authors from countries with a large number of contributions, such as Italy, India and Spain, which contribute 780,506 and 469 publications, respectively.

Table 1. Top 20 of the authors according to the H-index.

\begin{tabular}{|c|c|c|c|c|c|}
\hline Scopus ID & Indexed Name & H-Index & City & Country & University \\
\hline 35463345800 & Gräetzel, M. & 260 & Lausanne & Switzerland & $\begin{array}{l}\text { Ecole Polytechnique } \\
\text { Fédérale de Lausanne }\end{array}$ \\
\hline 55711979600 & Whitesides, G. & 229 & Cambridge & United States & Harvard University \\
\hline 56430045300 & Wang, Z. & 229 & Atlanta & United States & $\begin{array}{l}\text { Georgia Institute of } \\
\text { Technology }\end{array}$ \\
\hline 57201126795 & Cui, Y. & 190 & Menlo Park & United States & $\begin{array}{c}\text { SLAC National } \\
\text { Accelerator Laboratory }\end{array}$ \\
\hline 7103185149 & Antonietti, M. & 167 & Potsdam & Germany & $\begin{array}{c}\text { Max Planck Institute } \\
\text { of Colloids and } \\
\text { Interfaces }\end{array}$ \\
\hline 8922262400 & $Y u, J$. & 166 & Zhengzhou & China & Zhengzhou University \\
\hline 7403489871 & Zhao, D. & 153 & Melbourne & Australia & Monash University \\
\hline 56422845100 & Jiang, L. & 151 & Melbourne & Australia & Monash University \\
\hline 35463772200 & Nazeeruddin, $\mathrm{M}$. & 148 & Lausanne & Switzerland & $\begin{array}{c}\text { Ecole Polytechnique } \\
\text { Fédérale de Lausanne } \\
\text { University of }\end{array}$ \\
\hline 7102639063 & Lovley, D. & 145 & Amherst MA & United States & $\begin{array}{l}\text { Massachusetts } \\
\text { Amherst }\end{array}$ \\
\hline 56265688700 & Elimelech, M. & 141 & New Haven & United States & Yale University \\
\hline 57205523298 & Ramakrishna, S. & 138 & Singapore & Singapore & Faculty of Engineering \\
\hline 35416421800 & Tarascon J,.M. & 137 & Paris & France & Collège de France \\
\hline 7404285996 & Cheng, H. & 136 & Shenzhen & China & $\begin{array}{l}\text { Tsinghua-Berkeley } \\
\text { Shenzhen Institute }\end{array}$ \\
\hline 7101777373 & Beller, M. & 136 & Rostock & Germany & $\begin{array}{l}\text { Leibniz Institute for } \\
\text { Catalysis }\end{array}$ \\
\hline 35401845700 & Domen, $\mathrm{K}$. & 129 & Matsumoto & Japan & Shinshu University \\
\hline 8833978100 & Snaith, $\mathrm{H}$. & 129 & Oxford & United Kingdom & $\begin{array}{l}\text { University of Oxford } \\
\text { Max Planck Institute }\end{array}$ \\
\hline 35511455300 & Mölnwald & 128 & Potsdam & Germany & $\begin{array}{l}\text { of Colloids and } \\
\text { Interfaces }\end{array}$ \\
\hline 7004992352 & Blaabjerg, F. & 128 & Aalborg & Denmark & Aalborg Universitet \\
\hline 7005860537 & Jen, A. & 121 & Seattle & United States & $\begin{array}{c}\text { University of } \\
\text { Washington, Seattle }\end{array}$ \\
\hline
\end{tabular}

If we analyse the first three authors in Table 1, according to data published in Scopus:

- Michael Gräetzel (ID 35463345800) has 46 publications with more than 1000 citations. Two of them have more than 10,000 citations, [9] with 23,972 citations and [10] with 11,058 citations, has published with 2735 co-authors in 1653 publications indexed in Scopus, with 324,084 total citations.

- George M. Whitesides, (ID 55711979600) is the second largest H-index author with 1367 documents published in collaboration with 1494 co-authors. It has 236,664 citations. In total, 39 of their papers have more than 1000 citations, standing out [11] with 6401 citations. 
- Zhong Lin Wang (ID 56430045300) is the third largest H-index author. He has 27 documents with more than 1000 citations, for example [12] with 5492 citations. The author has published 1873 documents indexed in Scopus, in collaboration with 2681 coauthors, with 217,018 total citations.

Figure 4 shows the logarithmic distribution of the $\mathrm{H}$-index of the total of authors who publish about the study, 11,785 authors. The highest concentration of authors is shown in the lowest H-Index values, in the range from 0 to 9 , with 7349 authors $(62.36 \%$ of the total), of which 1.018 (8.60\% of the total) have an H-index of 0 and $1.843(15.60 \%$ of the total) have an $\mathrm{H}$-index of 1 . The ranges of $0-49$ have $96.87 \%$ of the total. There are only $0.36 \%$ of authors with an H-Index value greater than 99, the maximum H-index value being 256 of the author M. Gräetzel (ID Scopus 35463345800).

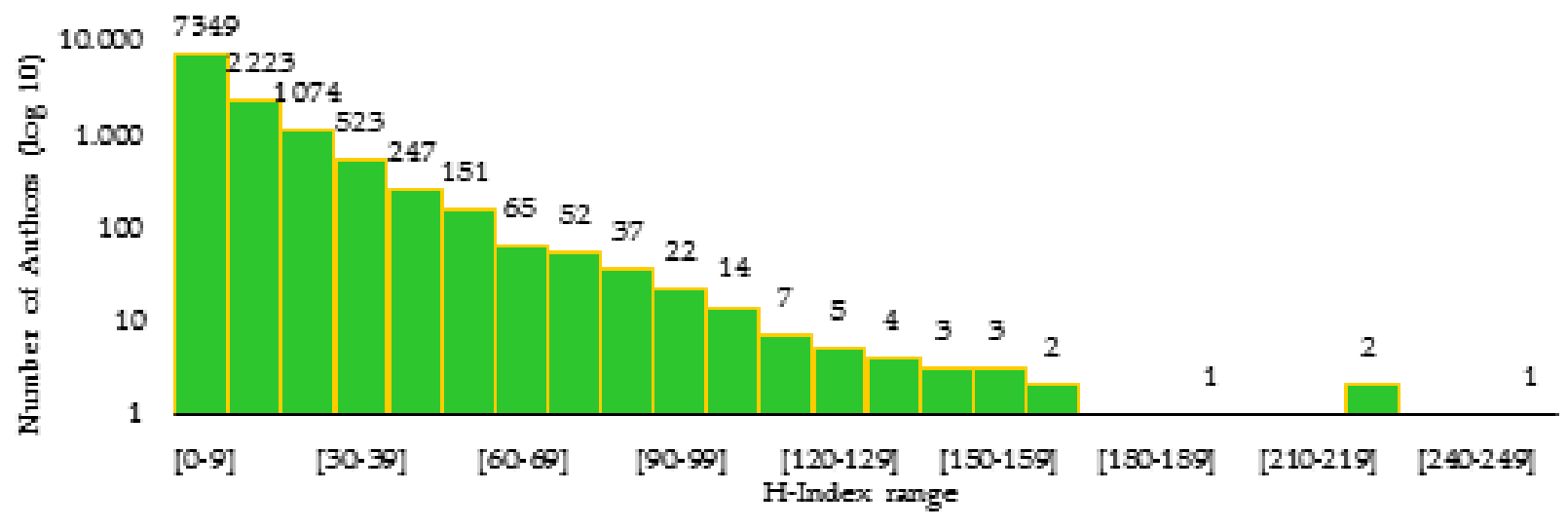

Figure 4. Distribution logarithmic by $\mathrm{H}$-index.

Figure 5 shows the distribution of the different publication formats of the documents found in the Scopus search. Articles are $95.02 \%$ of the total documents found $(13,925$ documents); $4.28 \%$ are Reviews (627 documents). The rest have a total contribution of less than $1 \%$.

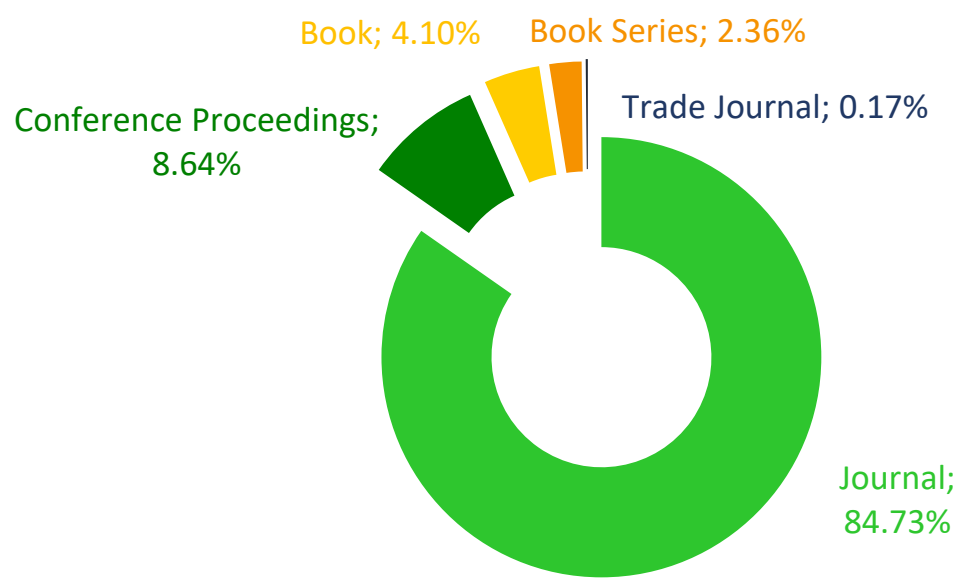

Figure 5. Representation of the type of documents published in Scopus.

The thematic studied in the different communities is published in 1146 different journals. Table 2 shows the 20 main journals indexed in Scopus that publish on this subject, all of them published in English. This table indicates the main reviews of these journals, as well as the latest available impact factor (2019). The journal with the highest number of publications is Renewable and Sustainable Energy Reviews, with 30\% of the total number of works (107 publications) and with two subject categories in the first quartile. The next journal in number of publications is the Journal of Cleaner Production, with $14.58 \%$ of the 
jobs (52 publications), almost half of the jobs that appear in the journal where the largest number of publications is concentrated. The third journal in number of publications is Applied Energy with $14.30 \%$ of the works (51 publications), followed by Renewable Energy with $13.74 \%$ (49 publications) and Sustainability with $12.90 \%$ (46 publications).

Table 2. Top 20 of the Scopus-indexed journals according to publish in the studio theme.

\begin{tabular}{|c|c|c|c|c|}
\hline ISSN & Journal & Category/Rank & $\begin{array}{l}2019 \text { Journal } \\
\text { Impact Factor }\end{array}$ & No. of Papers \\
\hline $1364-0321$ & $\begin{array}{l}\text { Renewable and } \\
\text { Sustainable Energy } \\
\text { Reviews }\end{array}$ & $\begin{array}{l}\text { Green \& Sustainable science \& } \\
\text { Technology / } 1 \text { of } 41 \text { (Q1) } \\
\text { Energy \& Fuels /7 of } 112 \text { (Q1) } \\
\text { Green \& Sustainable science \& }\end{array}$ & 12,110 & 107 \\
\hline $0959-6526$ & $\begin{array}{l}\text { Journal of Cleaner } \\
\text { Production }\end{array}$ & $\begin{array}{l}\text { Technology / } 6 \text { of } 41 \text { (Q1) } \\
\text { Engineering, Environmental/8 de } \\
53 \text { (Q1) }\end{array}$ & 7246 & 52 \\
\hline 0306-2619 & Applied Energy & $\begin{array}{l}\text { Environmental Sciences / } 19 \text { of } 265 \text { (Q1) } \\
\text { Energy \& Fuels/9 of } 112 \text { (Q) } \\
\text { Engineering, Chemical/6 of } 143 \text { (Q1) } \\
\text { Green \& Sustainable science \& }\end{array}$ & 8848 & 51 \\
\hline $0960-1481$ & Renewable Energy & $\begin{array}{l}\text { Technology/9 of } 41 \text { (Q1) } \\
\text { Energy \& Fuels / } 19 \text { of } 112 \text { (Q1) }\end{array}$ & 6274 & 49 \\
\hline $2071-1050$ & Sustainability & $\begin{array}{l}\text { Environmental Sciences/120 of } 265 \text { (Q2) } \\
\text { Green \& Sustainable science \& } \\
\text { Technology/26 of } 41 \text { (Q3) }\end{array}$ & 2576 & 46 \\
\hline $0301-4215$ & Energy Policy & $\begin{array}{l}\text { Environmental Sciences / } 40 \text { of } 265 \text { (Q1) } \\
\text { Energy \& Fuels / } 28 \text { of } 112 \text { (Q1) }\end{array}$ & 5042 & 41 \\
\hline $0360-5442$ & Energy & $\begin{array}{l}\text { Energy \& Fuels / } 20 \text { of } 112 \text { (Q1) } \\
\text { Thermodynamics / } 3 \text { of } 61 \text { (Q1) }\end{array}$ & 6082 & 28 \\
\hline 0196-8904 & $\begin{array}{l}\text { Energy Conversion and } \\
\text { Management }\end{array}$ & $\begin{array}{l}\text { Energy \& Fuels / } 11 \text { of } 112 \text { (Q1) } \\
\text { Thermodynamics / } 2 \text { of } 61 \text { (Q1) } \\
\text { Mechanics /3 of } 136 \text { (Q1) }\end{array}$ & 8208 & 26 \\
\hline 0360-3199 & $\begin{array}{l}\text { International Journal of } \\
\text { Hydrogen Energy }\end{array}$ & $\begin{array}{l}\text { Energy \& Fuels / } 30 \text { of } 112(\mathrm{Q} 2) \\
\text { Chemistry, Physical/48 of } 159(\mathrm{Q} 2) \\
\text { Electrochemistry/7 of } 27(\mathrm{Q} 2)\end{array}$ & 4939 & 22 \\
\hline 0038-092X & Solar Energy & Energy \& Fuels /35 of 112 (Q2) & 4608 & 22 \\
\hline $1996-1073$ & Energies & $\begin{array}{l}\text { Energy \& Fuels / } 63 \text { of } 112(\mathrm{Q} 3) \\
\text { Energy \& Fuels /31 of } 112(\mathrm{Q} 2)\end{array}$ & 2702 & 21 \\
\hline 0378-7788 & Energy and Buildings & $\begin{array}{l}\text { Construction \& Building Technology /7 } \\
\text { of } 63 \text { (Q1) }\end{array}$ & 4867 & 17 \\
\hline 0973-0826 & $\begin{array}{l}\text { Energy for Sustainable } \\
\text { Development }\end{array}$ & $\begin{array}{l}\text { Engineering, Civil/5 of } 134 \text { (Q1) } \\
\text { Green \& Sustainable science \& } \\
\text { Technology/21 of } 41 \text { (Q3) } \\
\text { Energy \& Fuels/51 of } 112(\mathrm{Q} 2)\end{array}$ & 3610 & 13 \\
\hline 0363-907X & $\begin{array}{l}\text { International Journal of } \\
\text { Energy Research }\end{array}$ & $\begin{array}{l}\text { Energy \& Fuels / } 46 \text { of } 112 \text { (Q2) } \\
\text { Nuclear Science \& Technology / } 1 \text { of } \\
34 \text { (Q1) }\end{array}$ & 3741 & 13 \\
\hline $0048-9697$ & $\begin{array}{l}\text { Science of the Total } \\
\text { Environment }\end{array}$ & Environmental Sciences/22 of 265 (Q1) & 6551 & 13 \\
\hline $1876-6102$ & Energy Procedia & Open Access & & 12 \\
\hline $0011-9164$ & Desalination & $\begin{array}{l}\text { Engineering, Chemical/11 of } 143 \text { (Q1) } \\
\text { Water Resources / } 2 \text { of } 94 \text { (Q1) }\end{array}$ & 7098 & 8 \\
\hline 1944-3994 & $\begin{array}{c}\text { Desalination and Water } \\
\text { Treatment }\end{array}$ & $\begin{array}{l}\text { Engineering, Chemical/118 of } 143(\mathrm{Q} 4) \\
\text { Water Resources/84 of } 94(\mathrm{Q} 4)\end{array}$ & 0.854 & 8 \\
\hline $1470-160 X$ & Ecological Indicators & Environmental Sciences / 61 of 265 (Q1) & 4229 & 8 \\
\hline $1865-3529$ & $\begin{array}{l}\text { Green Energy and } \\
\text { Technology }\end{array}$ & & & 8 \\
\hline
\end{tabular}

The magazines fall into one or more categories, except "Green Energy and Technology" magazine, which has no category or impact factor. This magazine is a Springer series con- 
sisting of 299 volumes published from 2008 to 2021 and is focused on energy with ecological and sustainable solutions with technological approaches and includes contributions to industrial engineering and engineering design. All categories present in the four journals with the highest number of publications are in the first quartile. Most of the categories are directly developed with sustainability or energy, except for categories such as "Engineering, Chemical" or "Chemistry, Physical", among others, which are indirectly related to the search keywords. Among the 20 most important journals, 50\% of the journals have all their categories in Q1, 10\% in Q2, 5\% in Q4 and 25\% of the journals have categories in different percentiles. Most of the publications listed in the table focus on journals with a high impact factor, with a value greater than 2.5 in all cases, except for the journal "Desalination and Water Treatment", which is in the fourth percentile. This fact confirms a preference for researchers to publish their work in journals with the most appropriate categories, the most favoured journals being the ones with a high percentile.

The languages present in the different publications are shown in Figure 6. This graph shows that the main language is English. It accounts the $98.15 \%$ of total papers. The preference of the researchers is English-language journals. German is the second language for publications, and it contributes to $0.52 \%$ of the total publications. There are the same number of publications in languages such as Chinese or Spanish (16 works), less than $0.38 \%$ of the total. In addition, there is a wide variety of languages, such as Portuguese, French, Italian, Japanese or Russian, although the number of such publications is exceedingly small and negligible, 12 publications in the largest case $(0.28 \%)$.

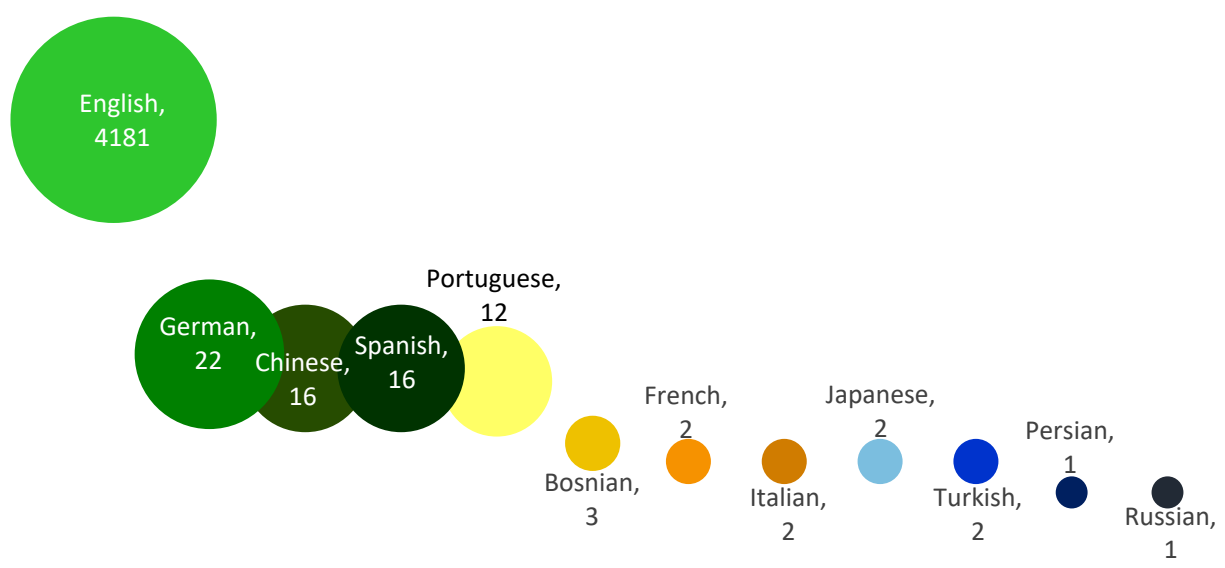

Figure 6. Representation of language of publications.

\subsection{Establishing and Analysis of Communities}

The search developed in this work yields a total of 4260 documents, among which 2195 relationships are established. Through a filtering process, documents that do not present relationships with others are eliminated, considering that most of these works are in the distribution belt. Finally, the documents between which there are relationships, and which essentially form the core of the distribution, are maintained, Figure 7 . The total number of documents studied is reduced to $26.90 \%$ of the total (1146 works) and the existing distribution presents 1872 relationships (85.28\% of the total). The size of the nodes depends on the collaborations between authors and not only on the number of citations in the documents. A document can be highly referenced, but if the authors work alone and do not interact with others, it has a smaller node than another publication with fewer references, but in which the authors develop a greater number of collaborations. In the spatial distribution of the documents, nine communities constituted by the works can be differentiated, between which there are multiple interactions. 


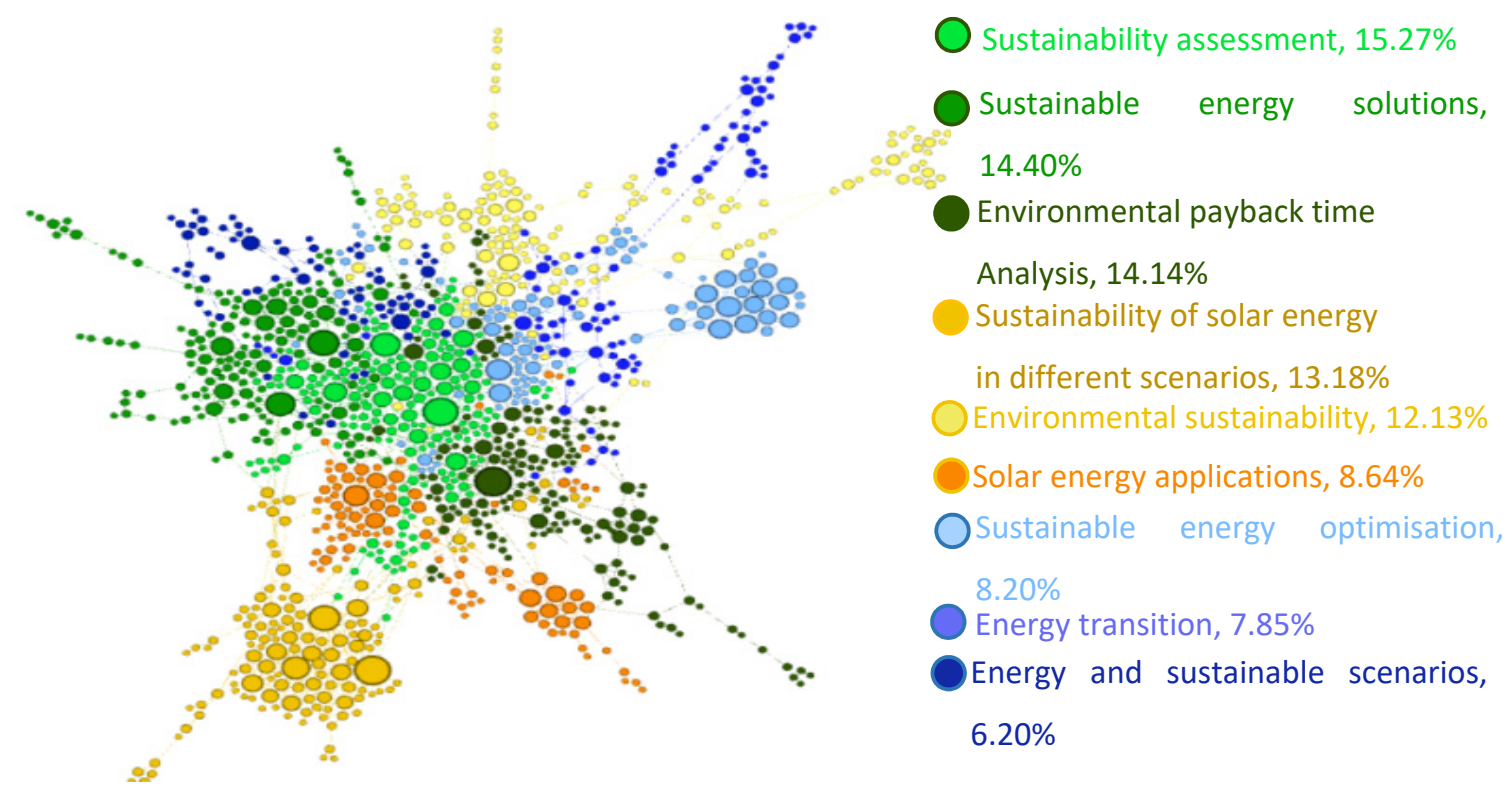

Figure 7. Distribution of the nodes studied.

In the spatial representation of the nodes, it is difficult to establish the size of each one of the communities, due to the interrelation between them. Among the nine communities present, five of them have a comparable size and are made up of more than $12 \%$ of the documents studied. The Sustainability assessment community stands out notably, comprising $15.27 \%$ of the works, followed by Sustainable energy solutions (14.40\%) and Environmental payback time analysis $(14.14 \%)$, of equivalent size. The next two communities are slightly smaller in size, they are the Sustainability of solar energy in different scenarios $(13.18 \%)$ and Environmental sustainability (12.13\%) communities. There are three other communities with an equivalent size and less than 9\%, which are the Solar energy applications (8.64\%), Sustainable energy optimization $(8.20 \%)$ and the Energy transition community $(7.85 \%)$. The smallest community is Energy and sustainable scenarios and is made up of 71 documents that represent $6.20 \%$ of the total.

In the studied documents, a total of 2746 keywords are presented, including a minority of acronyms. Most of the acronyms have been replaced by their equivalent words and the hyphens have been eliminated, besides, all the words in the singular have been considered, although their expressions in the plural have been counted. Figure 8 shows the global representation of these keywords, considering that their size is related to their frequency of appearance. Figure 9 represents the 10 most repeated keywords globally and their number of occurrences.

In the previous figures, the word with the highest number of repetitions is Sustainability, with 286 occurrences and it represents more than $10 \%$ of the total of keywords, being usually the most repeated in all communities. The number of repetitions of this word is much higher than the repetitions of the following word, Renewable energy ( $6.5 \%$ of the total words), and the difference in sizes in the global representation is very remarkable. The third word in global importance is Solar energy and its number of appearances is less than half of the repetitions of the most important word, $4.6 \%$ of the total. The rest of the words have a repetition number fewer than one hundred, as in the case of Energy $(2.95 \%)$ or Photovoltaic $(2.91 \%)$. The 10 most globally repeated words are usually among the 10 most repeated in each community, and they constitute $37 \%$ of the total number of existing words. All of them are related to the theme of sustainability, renewable energy and concepts related to solar energy, such as Solar energy or Solar photovoltaic (1.49\%). The rest of the words appear on a small number of occasions, so their size compared to the rest is much smaller and they represent less than $1 \%$ of the total keywords. 


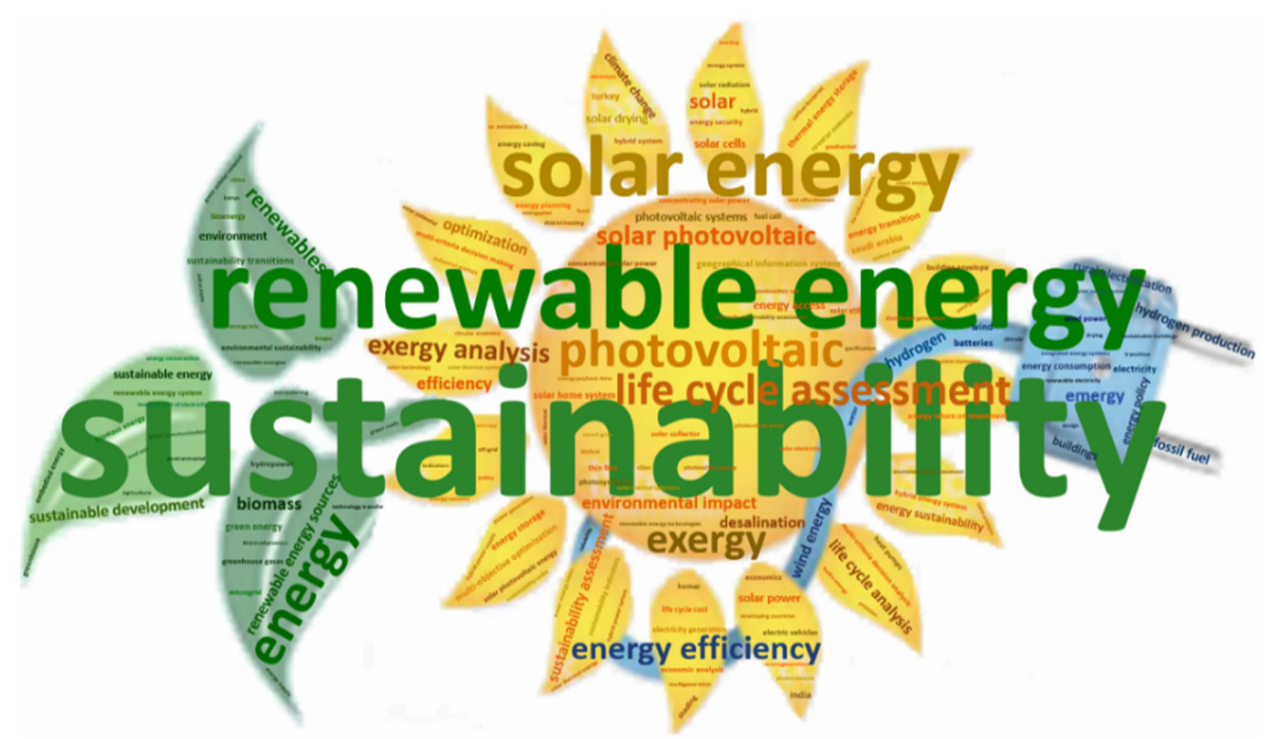

Figure 8. Representation of the most globally representative keywords.

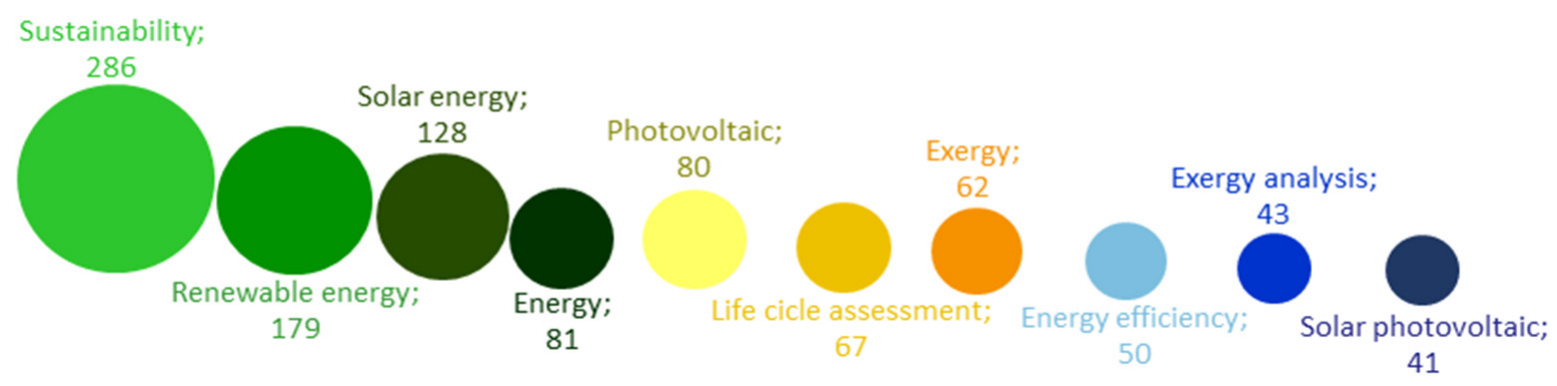

Figure 9. Representation of the 10 most repeated keywords globally.

The documents that constitute the main nodes of each community have been carefully studied. Through this study, the most important achievements of each investigation, its scope and implications in current and future society can be determined.

\subsubsection{Community Sustainability Assessment}

The evaluation of sustainability has been widely studied, different methods, scenarios and parameters are established based on this concept. Additionally, it has been evaluated in different time horizons: current, short, medium, and long term. Despite this, establishing a single standard or a common consensus on the indicators to be used for sustainability assessment is a current challenge. So, it is a widely discussed topic and a fact that is observed in this community. It brings together different examples of research, which aim to guide and evaluate energy systems towards energy sustainability.

This community is made up of 175 documents. It is the first community in size with a contribution of $15.27 \%$ of published documents. This community is in the main area of the distribution (Figure 7), highlighting the existing influence with the larger communities such as the Sustainable energy solutions and Environmental payback analysis communities. It also maintains important relationships with the Solar energy applications community and the Energy optimization community. This community has an influence on the rest of the communities, since the main issue addressed in this community can be considered a cross-cutting issue to those that make up the rest of the communities. Figure 10a shows the concentration of the nodes of this community. Three larger nodes are observed compared to the rest: 
- "Sustainability assessment of energy systems: Integrating environmental, economic and social aspects" with 258 cites [13].

- "Using a sustainability index to assess energy technologies for rural electrification" with 50 cites [14].

- "Energy system assessment with sustainability indicators" with 168 cites [15].

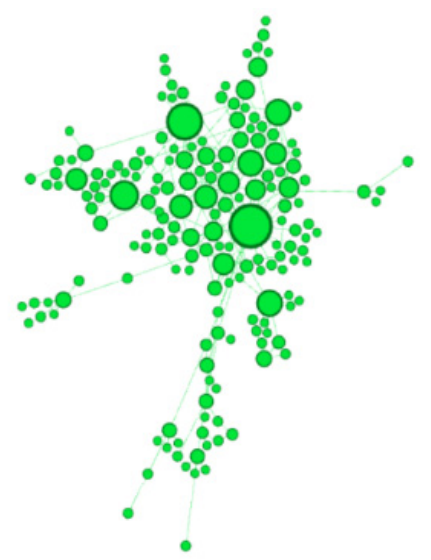

(a)

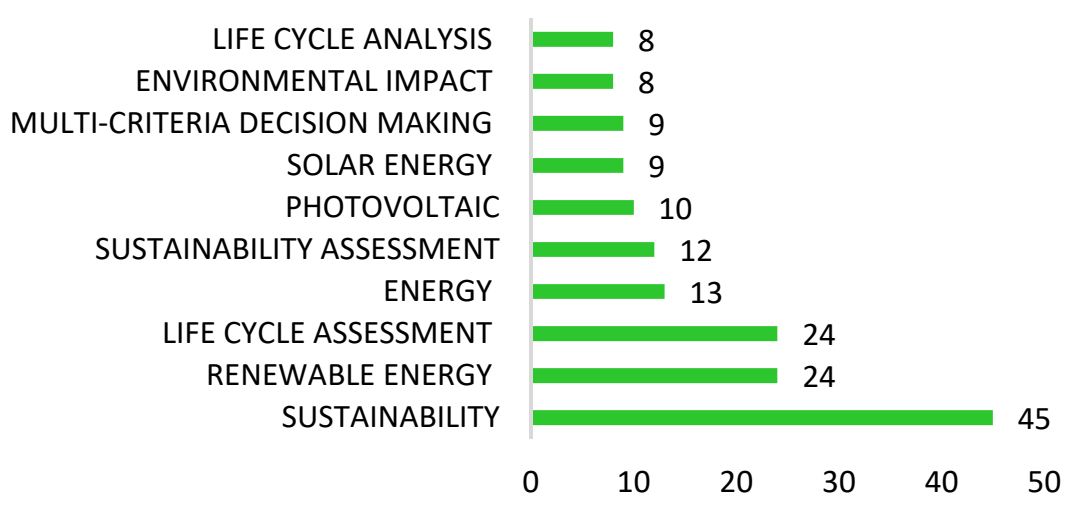

(b)

Figure 10. Sustainability assessment: (a) Manuscripts published; (b) keywords.

Figure $10 \mathrm{~b}$ represents the top 10 keywords of this community and their number of appearances, which constitute $6 \%$ of the total keywords. Among these 10 words, sustainability and renewable energy are the two words with the highest frequency of appearance at the global level and both represent $35 \%$ of the total of the words present in this community. Seven of the 10 most repeated words in this community are among the globally repeated words (Figure 7), as they consider issues related to the evaluation of sustainability, one of the most studied aspects in the documents discussed.

E. Santoyo-Castelazo and A. Azapagic (2014) considers the life cycle, its cost, and the evaluation of social sustainability [13]. For this evaluation, a multicriteria decision system is established, and it is applied to different scenarios with different energy systems. This methodology allows decision-makers to incorporate different preferences for sustainability criteria, as well as to identify the most sustainable options. For its analysis, it establishes some environmental, economic, and social indicators, in addition to energy technology, two possible scenarios (renewable and fossil energy) in Mexico and their time horizon. The results highlight the need for support or compensation to achieve the most sustainable option, energy policies that help sustainable development being necessary.

With the aim to meet the energy and environmental objectives set by the European Union for 2020, it is necessary to provide the governments with accurate energy studies, which assist them to make decisions regarding changes in energy policy. D. Streimikiene and collaborators (2012), a decision support framework is developed to choose the most sustainable energy technologies using two multi-criteria methods [16]. Both decision methods show that renewable energy sources should be the ones chosen to address energy demand. Solar and hydraulic energy stand out ahead of the rest of renewable energy sources, with fossil fuels being the least sustainable choice.

The evaluation of the sustainability of energy technologies applied in rural electrification is developed by B. Mainali and S. Silveira [14]. One of the most important energies and technological challenges of today is to give access to electricity to the most isolated and disadvantaged populations. In this work, the sustainability index of energy technology is evaluated, using multivariate techniques called Principal Component Analysis (PCA), which are applied to an area of India. In this case, the results indicate that the technologies with the highest sustainability yields are those based on biomass, followed by hydroelectric 
ones. Solar, wind, and their hybrids have the best sustainability considerations over time. It is confirmed that in the rural context and without strong political support, emerging renewable technologies have difficulties competing with fossil-based technology since their excessive cost must be reduced. By establishing an individual consumption scenario, solar, wind, biomass and fossil energy are valued. In [15] the study is carried out in the special case of an island, using environmental, social, and economic criteria, to which the available resources are added.

Another publication from this community develops and analyses a model for prioritizing available renewable sources, to establish a sustainable energy policy in a country like Malaysia [17], where it is estimated that $90 \%$ of the energy consumed comes from fossil sources. Technical, economic, social, and environmental aspects are considered in the analysis. The study concludes that photovoltaic and hydraulic energy are the best options for sustainable development, so developing countries should rely on these energy sources to ensure sustainable growth.

\subsubsection{Community Sustainable Energy Solutions}

Currently, the growth of less developed countries implies an increase in global energy demand, for which sustainable energy solutions must be considered. In this community, these types of solutions are established through different alternatives, aimed to reduce the environmental impact of power generation. To achieve this goal, sustainable energy sources are proposed, with the disadvantage of being intermittent and fluctuating.

This community is made up of 165 documents. It is the second community in size, with a contribution of $14.40 \%$ of published documents. It is located at one of the extremes of the total distribution (Figure 2) because its relationship is established with the communities' Sustainability assessment, Solar energy applications and Sustainability of solar energy in different scenarios.

Figure 11a shows the concentration of the nodes, where there are six medium-sized nodes and three main nodes. The three nodes are:

- " "A review on clean energy solutions for better sustainability" with 196 cites [18].

- "A key review on exergetic analysis and assessment of renewable energy resources for a sustainable future" with 584 cites [19].

- "Energy, exergy, environmental, enviroeconomic, exergoenvironmental (EXEN) and exergoenviroeconomic (EXENEC) analyses of solar collectors" with 39 cites [20].

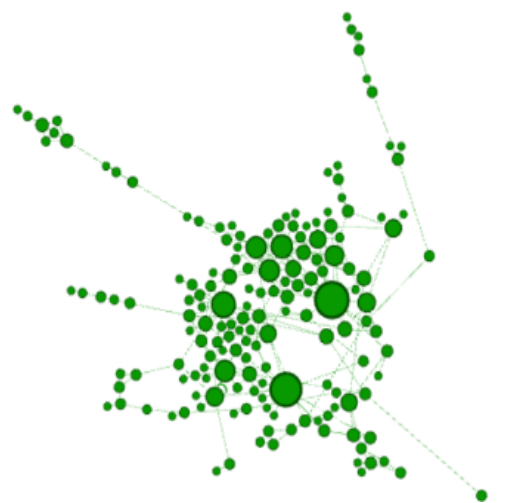

(a)

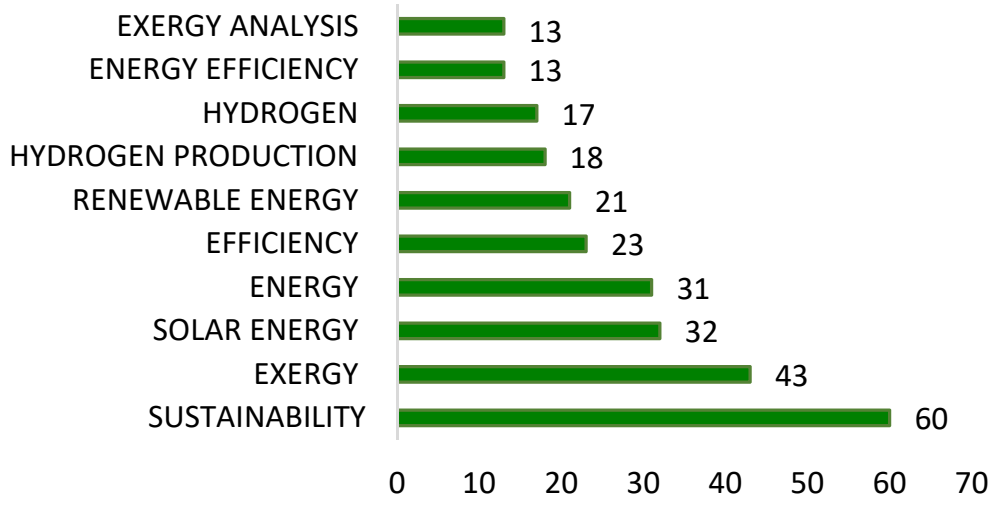

(b)

Figure 11. Sustainable energy solutions: (a) Manuscripts published; (b) keywords.

Figure $11 \mathrm{~b}$ represents the top 10 of the most repeated keywords in the community, with $9.8 \%$ of the total keywords. The most repeated word in this community is sustainability, being also the most repeated word globally. Besides, its frequency of appearance represents $22 \%$ of the repetitions that raise the top 10 words in this community, a frequency higher 
than that present in other larger communities. Other words represented in the top 10 of this community are located among the top 10 of global keywords. An example of this is the words Solar energy, energy, renewable energy efficiency or energy analysis. The second word with the highest appearance is exergy $(16 \%)$. It is not located among the five with the highest global frequency, but it is among the 10 most repeated. Exergy is a concept of vital importance in this community as it is considered a key factor in energy efficiency, its quantification and evaluation. Among the top 10 keywords there are only two concepts, hydrogen production $(6.6 \%)$ and hydrogen $(6.2 \%)$ that are not among the 10 global keywords, but among the 25 with the globally highest repetition.

The PhD. Arif Hepbaşli is an author with several publications among the most important ones in this community. In 2005 he developed an exergy analysis through the thermodynamic simulation of different energy systems [21]. Exergy allows the measurement of the maximum useful work that can be done by a system that interacts with an environment, under pressure and temperature conditions, and it is used to improve the concept of active energy [22]. One of his most important publications is [19], which establishes an evaluation from the perspective of the exergetic efficiencies of solar energy systems, wind energy, geothermal energy, biomass, and other hybrid renewable energy systems. It should be noted that the system with a hybrid solar collector is the most efficient $(13.3 \%)$, while the system with a solar collector has the lowest efficiency $(4.4 \%)$. In wind systems, greater efficiency is obtained at high wind speeds (55\%), compared to low wind speed systems $(40 \%)$. These results can be useful to identify opportunities for energy efficiency and/or energy conservation, as well as to dictate the correct energy and exergetic management strategies in a country.

Subsequently, the researcher Hakan Caliskan (2017) performs a similar review on systems with solar collectors [20]. This publication includes analyses of exergy, environmental, energy-based environmental analysis (enviroeconomic), exergy-based environmental analysis (EXEN), exergy-based environmental and economic analysis (EXENEC). The results show that for a better evaluation, environmental and environmental-economic aspects must be considered, all of them based on exergy.

The most important publication of this community is a review, where energy sources are classified, to establish improvements according to technical, economic, and environmental performance criteria [18]. The results show that the comparison criteria indicate the different levels of applicability of each type of energy. If environmental impacts are considered, the most applicable energies are geothermal energy, wind energy, hydro (river run), oceanic, solar, hydroelectric, nuclear, and lastly, biomass energy.

Exergy is also essential in the study of the energy requirements of buildings, as it is a very important factor in the global energy framework [22]. Currently, buildings consume $40 \%$ of the world's energy, which is used mainly for heating, ventilation, and air conditioning (HVAC). Therefore, low exergy systems (LowEx) are proposed, implying small energy values, which could be achieved with sustainable sources, reducing $\mathrm{CO}_{2}$ levels.

The current energy problem could be solved, from the point of view of sustainability, using hydrogen as fuel for energy generation [23]. Some of the advantages of this energy source are its elevated level of conversion, its abundance, the easiness to be transported over long distances, its easy conversion to other energy sources and its HHV (higher heating values) and LHV (lower heating values) higher than those present in conventional fossil fuels. Among the different methods to produce hydrogen, the photocatalytic methods for the separation of water stand out [24]. Research reveals that the efforts should be focused on studying new materials and photocatalysts, which allow creating photocatalytic systems with great stability, having appropriate forbidden bands and with correctly located valence and conduction bands. All possible advances in this field will make the establishment of more efficient photocatalytic water separation processes and greater efficiency in hydrogen production systems possible. 


\subsubsection{Community Environmental Payback Time Analysis}

The production of photovoltaic solar energy is considered clean energy, but throughout its life cycle (LCA) some effects deviate from the concept of clean production. In this community, some of the multiple sustainability evaluation indicators that exist in the literature are raised and that allows, through life cycle analysis, the evaluation of and reduction in the environmental impact of the energy production process.

This community is made up of 162 documents. It is the third community in size with a contribution of $14.14 \%$ of published documents. In Figure 7 , it is located at one extreme because the topic discussed maintain relationships with the communities: Sustainability assessment, Environmental sustainability, Solar energy applications, Energy transition and Sustainable energy optimisation. Figure 12a shows the concentration of the nodes, the main node and 11 medium-sized nodes are observed. The three main nodes are:

- "Review on life cycle assessment of energy payback and greenhouse gas emission of solar photovoltaic systems" with 343 cites [25].

- "The sustainability indicators of power production systems" with 81 cites [26].

- "Environmental payback time analysis of a roof-mounted building-integrated photovoltaic (BIPV) system in Hong Kong" with 119 cites [27].

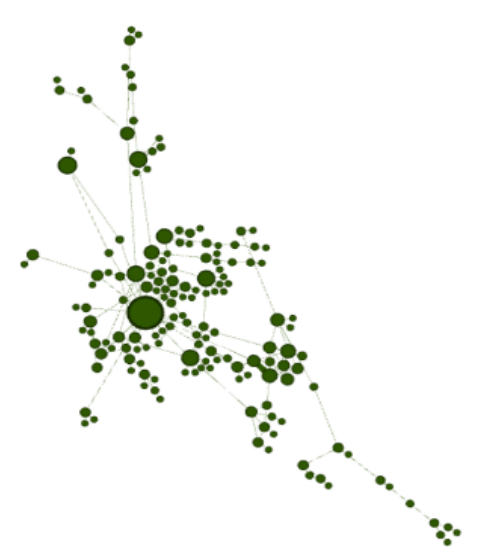

(a)

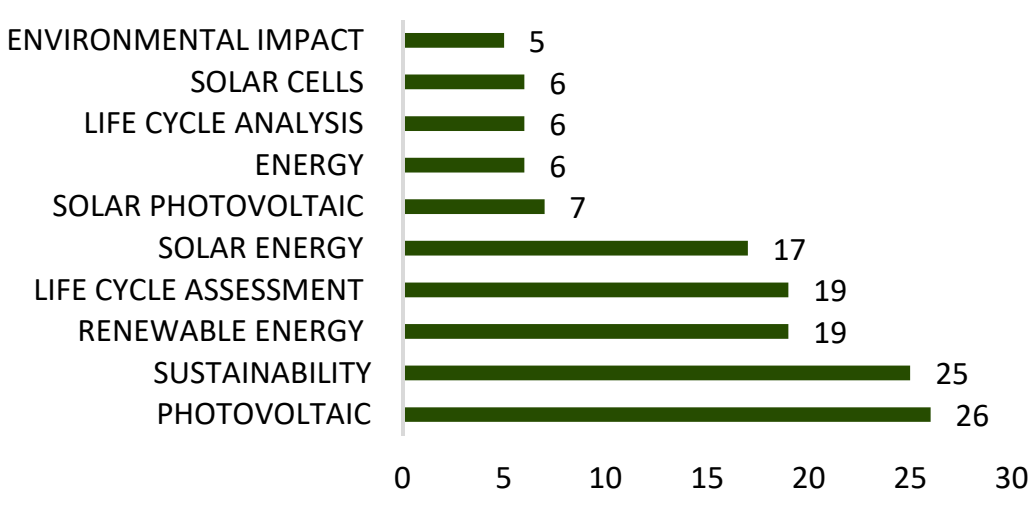

(b)

Figure 12. Environmental payback time analysis: (a) Manuscripts published; (b) keywords.

Figure $12 \mathrm{~b}$ shows the top 10 keywords with a representation of $4.9 \%$ of total keywords. The most common word is Photovoltaic, with a $3.6 \%$. of the total words present in this community. In contrast to what happens in most communities, the most repeated word is not the most frequent globally, although it is the fifth in the global ranking. The following keywords according to the appearance in this community are sustainable (3.5\%) and renewable energy $(2.7 \%)$, being the two most globally frequent keywords. The rest of the words that make up the top 10 are among the 20 most frequent words, except for solar cells $(0.8 \%)$ which is among the 50 most globally frequent words ( $8 \%)$.

Sustainability can be assessed using the energy payback time indicator (EPBT) and the rate of emission of greenhouse gases (GHG), as in [25]. In this work, several photovoltaic systems are compared: mono-crystalline, multi-crystalline, amorphous-silicon (a-Si), CdTethin film (CdTe), CISthin film (CIS), high-concentration PV, heterojunction solar cells and dye-sensitized solar cells. A summary of the results extracted from this comparison is shown in Table 3. It should be noted that the new production processes of solar cells and their application in technologies such as building integrated photovoltaic (BIPV) or PV-thermal (PV-T) can help to reduce the life cycle energy and unwanted environmental impacts of photovoltaic systems. 
Table 3. Sustainability indicator data [25].

\begin{tabular}{cccc}
\hline Solar Cell & $\begin{array}{c}\text { LCA } \\
\mathbf{( M J} / \mathbf{m}^{\mathbf{2}} \mathbf{)}\end{array}$ & $\begin{array}{c}\text { EPBT } \\
\mathbf{( Y e a r )}\end{array}$ & $\begin{array}{c}\text { GHG } \\
\mathbf{( g ~ C O} \text {-eq./kW h) }\end{array}$ \\
\hline Mono-crystalline & $2860-5253$ & $1.7-2.7$ & $29-45$ \\
Multi-crystalline & $2699-5150$ & $1.5-2.6$ & $23-44$ \\
& $710-1990$ & $1.8-3.5$ & $18-50$ \\
CdTe thin film & $790-1803$ & $0.75-2.1$ & $14-35$ \\
CIS thin film & $1069-1684$ & $1.45-2.2$ & $10.5-46$ \\
\hline
\end{tabular}

L. Lu and H.X. Yang carried out a study in 2010 where they analysed the EPBT indicator and the greenhouse gas recovery time (GPBT) of a $22 \mathrm{KW}$ BIPV system, located on the roof of a building and connected to the network in the city of Hong Kong [27]. In this type of system, the orientation and location of the panels notably influence the indicators. In the same installation, values range from 7.1 years (optimal orientations) to 20 years (less favoured orientations). Therefore, the locations and orientations where the highest incident solar irradiance is captured must be selected, being a fundamental concept to obtain better sustainable results.

Other sustainability indicators such as Unit energy cost, $\mathrm{CO}_{2}$ emissions, Availability, Efficiency, Freshwater consumption, Land use, and Social influences, [26] are also studied. From the comparative analysis of these indicators, it can be deduced that wind power plants are the most sustainable, followed by nuclear, hydroelectric, and photovoltaic plants. The difficulty in the availability of geothermal resources is remarkable, being into the least sustainable, with values like those of natural gas and fuel cell technologies. Coal-fired power plants are at the least sustainable base of the analysed technologies, and the disuse of coal is forecast by 2050.

In [28], the environmental and economic impact of two photovoltaic plants located in Milan and Palermo (Italy) is analysed. It is concluded that with $134 \mathrm{MW}, 8.5$ teq. of $\mathrm{CO}_{2}$ can be saved per KW installed, generating a positive economic net flow of $€ 2000$ per $\mathrm{KW}$ installed.

In recent years, reviews have been carried out on the relationship between renewable energies and sustainability, considering the economic, social, and environmental dimensions, an example of this is [29]. This work is the first critical review that considers these three aspects simultaneously, showing that the countries with the highest production in terms of renewable energy and sustainability are the United States, the European Union, China, and the United Kingdom. In developed countries, a greater variety of renewable energy sources are used, with wind and solar energy being among the most investigated. Furthermore, the dimension with the most weight within sustainability is environmental, followed by economic.

To achieve sustainability, it is essential to promote sustainable electricity generation in the industry, which represents $37 \%$ of the total energy consumption. Currently, the goal is that solar heat could replace fossil fuels, which are used to satisfy $80 \%$ of the industrial demand, so the integration of a sustainable thermal energy storage system is essential. Koçak, Fernandez and Paksoy (2020), a global review of current research on sensitive thermal energy storage (STES) and its applications in industrial solar heat processes is presented [30]. At this moment, solar applications in industry are designed for low temperature processes (less than $150{ }^{\circ} \mathrm{C}$ ) and more than a half are being used to supply hot water up to $95^{\circ} \mathrm{C}$ in pasteurization, cleaning, and preheating processes. The STES systems significantly reduce the cost of fuel and $\mathrm{CO}_{2}$ emissions. In the future, if the applications of industrial solar heat strengthen, the objectives of climate change could be achieved.

\subsubsection{Community Sustainability of Solar Energy in Different Scenarios}

Promoting access to electricity supplies is a great concern of governments. Access to electricity is a challenge in some rural areas far from cities, where in most cases the best 
option is an off-grid renewable energy system. In this community, studies are established in different scenarios, which aim to solve access to electricity. Possible improvements to be implemented in future facilities are identified, considering that to achieve a sustainable energy supply, complex institutional, economic, environmental, and socio-cultural interactions must be developed.

This community is made up of 151 documents. It is the fourth community in size with a contribution of $13.18 \%$ of published documents. This community mainly maintains relations with the Sustainable energy solutions, Energy transition and Sustainable energy optimization communities (Figure 7). Figure 13a shows the concentration of the nodes, where three of them are the main ones, and the rest are medium-sized nodes. These three nodes are:

- "Sustainability of off-grid photovoltaic systems for rural electrification in developing countries: A review" with 32 cites [31].

- "Renewable rural electrification: Sustainability assessment of mini-hybrid off-grid technological systems in the African context" with 88 cites [32].

- "Sustainability assessment of renewable energy projects for off-grid rural electrification: The Pangan-an Island case in the Philippines" with 50 cites [33].

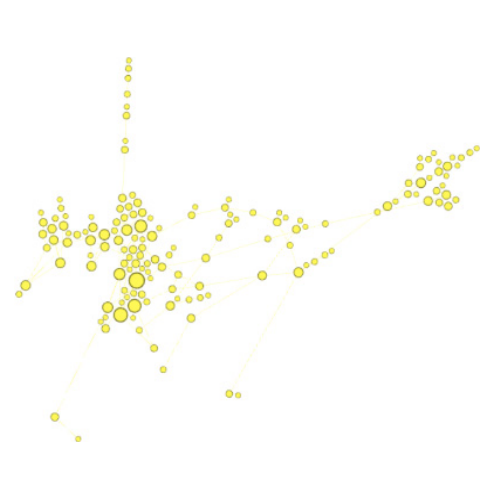

(a)

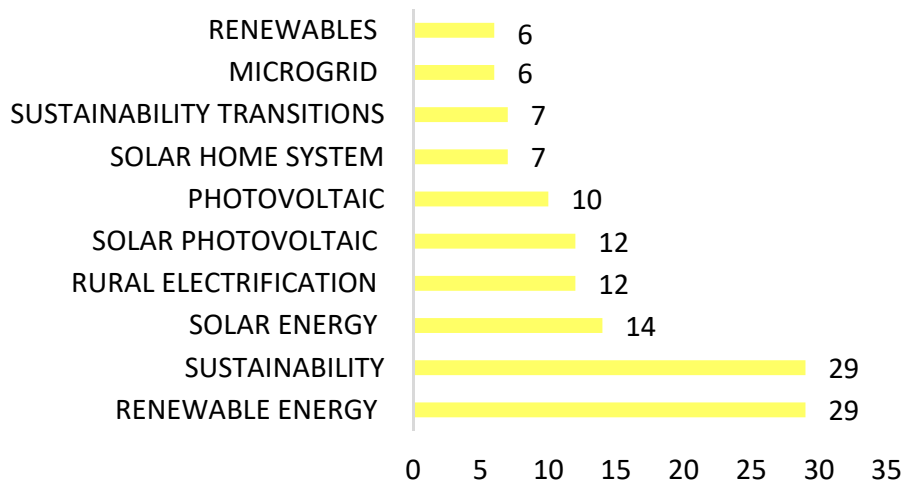

(b)

Figure 13. Sustainability of solar energy in different scenarios: (a) Manuscripts published; (b) keywords.

Figure $13 \mathrm{~b}$ represents the 10 most frequent keywords of this community, which constitute $4.8 \%$ of the total, a proportion to that of the previous community, as they are of similar sizes. The keywords renewable energy and sustainability are the most repeated, with the same frequency of appearance in the community (3.9\%). These words are also the two most globally important keywords, a fact that is usually the general tone in most communities. Other words such as Solar energy $(1.9 \%)$, solar photovoltaic $(1.6 \%)$ and photovoltaic $(1.3 \%)$, are among the 10 most globally frequent. Most of the words that make up the top 10 of this community deal with concepts related to solar energy or renewable energies, such as the solar home system $(0.9 \%)$, sustainability transitions $(0.9 \%)$, microgrid $(0.8 \%)$ or renewables $(0.8 \%)$. All the words in the top 10 of this community are among the 50 most globally repeated.

S. Feron (2016) presents a review of the limitation of sustainability in a rural electrification scenario based on photovoltaic systems without connection to the grid [31]. Sustainability indicators are analysed from an institutional, economic, environmental, and sociocultural perspective. From the institutional aspect, the countries with the least rural electrification are the least stable. Decentralized institutions do not consider the needs or lack of specialized knowledge of the users, so there is a lack of coordination between local and national governments. From an economic point of view, there are drawbacks since photovoltaic systems require an initial investment. In the long term, they are profitable and more environmentally friendly, contrary to traditional energy systems. The low environmental awareness in rural areas, where the socio-economic level is low, does not help to 
implement sustainable energy systems. To overcome all these inconveniences, it is necessary to coordinate and implement economic and environmental policies, through subsidies or microcredits, as well as environmental awareness. In line with this research, Ulsrud et al. (2015) discusses a solar power model that is developed and tested in collaboration with a Kenyan community and a team of scientific and technical experts [34]. The model is based on villages located in areas with dispersed settlement patterns, representative of large parts of Africa. This research shows that to plan and develop an energy supply system it is necessary to consider the sociocultural and geographical context of the area.

The case study of different remote scenarios reflects that to develop renewable systems in remote areas in a sustainable way, the connection to the national grid should be considered in its design [31,32]. Brent and Rogers (2010) the sustainability of an off-grid mini-hybrid system for a rural village in South Africa is evaluated [32]. The system is made up of wind, solar and lead-acid batteries. The results show that it is not a viable system, due to the lack of economic subsidies that minimize the costs of supply in the short and long term (maintenance of the installation). The problems derived from the technological complexity to be developed must also be solved. A centralized off-grid solar plant on Pangan - an island in the Philippines-is presented in [33]. The target group of this project were users with low economic and cultural resources, whose main source of income was fishing. These facilities require an initial investment and capital for their maintenance. Due to the peculiarities of the location, no benefits were reported to compensate for the minimal expense in electricity consumption, which makes this type of facility unviable. Another case arises Amran et al. (2020), where a system in Saudi Arabia, a country in a phase of economic and social growth, is studied [35]. So far, the energy consumption of this country has been produced using natural gas and oil from its fields, which has significantly increased $\mathrm{CO}_{2}$ emissions. These facts motivate government leaders of countries like this to consider the need to build a sustainable energy network, supported by renewable energy sources. In the work outlined Dauenhauer et al. (2020), it is determined that a compendium between solar energy and photovoltaic energy can make the Saudi Arabian electricity grid more sustainable, allowing the satisfaction of its internal demand and even selling energy abroad [36]. Another country analysed in this community is Malawi, where $91 \%$ of its population does not have access to electricity. A sustainability analysis of 65 off-grid projects is presented in [36]. The electricity supply of these projects is based on photovoltaics panels. The analysis uses a novel assessment methodology that includes organisational, social, technical, and economic factors. The sustainability of such projects is found to be low. The most unfavourable aspect is the economic factor, due to the fact that only 9 of the 65 projects covered $80 \%$ of their long-term cost.

\subsubsection{Community Environmental Sustainability}

The main problem with renewable energy sources lies in making them competitive and efficient, in comparison with conventional energy sources, keeping in mind their environmental sustainability. In this community, the documents that are published relate environmental sustainability with solar energy production. Currently, there is no agreed upon method in the scientific community to assess sustainability, only indices that allow its assessment from different perspectives. One of the most widely used concepts in this community for the assessment of environmental sustainability is the emergency. This word was defined in 1996 by Howard T. Odum as the sum of all energy inputs required directly or indirectly in a process, to provide a given output, where the inputs are expressed in the same form, usually solar energy [37].

This community is made up of 139 documents. It is the fifth community in size with a contribution of $12.13 \%$ of published documents. This community maintains a relationship with the Solar energy applications, Environmental payback time analysis and Sustainability assessment communities mainly (Figure 7). Figure 14a shows the concentration of the nodes, where there are three main nodes, while the rest are medium-sized nodes. The three nodes are: 
- "Monitoring patterns of sustainability in natural and man-made ecosystems" with 293 cites [38].

- "Environmental sustainability of wind power: An emergy analysis of a Chinese wind farm" with 49 cites [39].

- "Emergy evaluation of the performance and sustainability of three agricultural systems with different scales and management" with 122 cites [40].

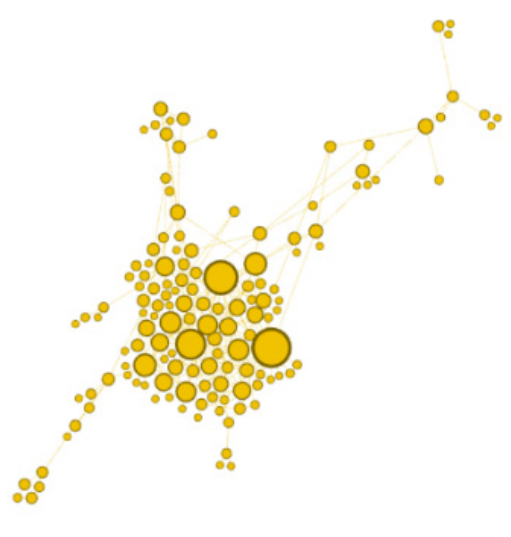

(a)

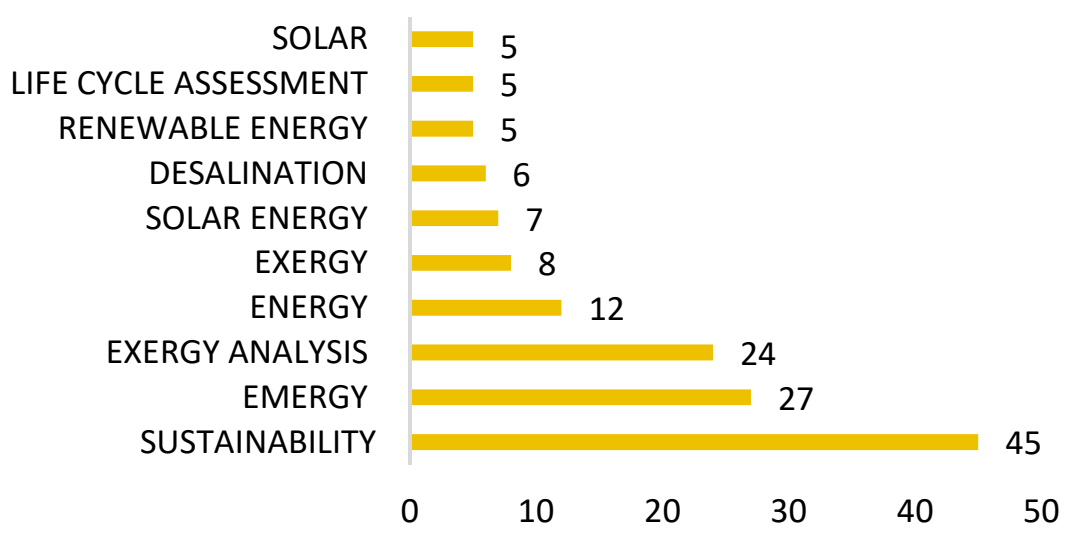

(b)

Figure 14. Environmental sustainability: (a) Manuscripts published; (b) keywords.

Figure $14 \mathrm{~b}$ shows the top 10 of the most frequent keywords in this community, representing $21.9 \%$ of the total words. The word with the highest number of repetitions is sustainability, which represents $6.83 \%$ of the words that make up the community and which coincides with the most globally repeated word. Among the 10 most important words in this community, there are seven that also coincide with the 10 most globally frequent, although in a different order, as in exergy analysis (3.6\%), energy (1.82\%), exergy $(1.21 \%)$ and solar energy $(1.06 \%)$. The second most repeated word in this community is emergy, which represents $4.10 \%$ of the total of the words in this community (less than $1 \%$ global) and it is not among the top 10 global keywords, but in position 14. Other words that appear in the top 10 of the words of the community and not among those that make up the top 10 of global words are desalination $(0.91 \%)$ and solar $(0.76 \%)$, despite these being among the 25 most globally repeated and are strongly related to concepts of environmental sustainability, such as those treated in this community.

S. Ulgiati and M.T. Brown (1998) in [38] the oscillating state of environmental sustainability is studied through the emergency indicator, considering that a system is sustainable when it comprises ecological and economic compatibility. By studying the emergy indices, as the environmental load index, the emergency return ratio, and the sustainability index (defined as the relationship between the Emergency Return Ratio and the Emergy Investment Ratio), the behaviour of the system can be established, and appropriate policy measures can be applied to steer the system towards more sustainable behaviours. In this paper, seven countries with major differences in industrial development and natural resources are analysed (Papua New Guinea, Ecuador, Thailand, Mexico, the United States, Italy, and Taiwan). As basic energy resources dwindle, society will be driven to more efficient conversion systems and greater dependence on locally available renewable emergency sources.

Other studies analyse emergency indicators in other fields of study and different scenarios. Yang et al., (2013) study the emergency indices from the ecological perspective for the case of a wind farm in Guangxi, China [39]. Five indices are used for this study: The Renewable Percentage, Emergency Performance Ratio, Environmental Burden Ratio, Emerging Investment Ratio Emergy In-vestment Ratio, and the Emerging Sustainability Index. The comparison with other renewable systems shows superiorities, in terms of 
sustainability and ecological cost, of wind energy, solar thermal energy and photovoltaic technologies. These results can help to improve the planning of future wind farms and to increase their sustainability.

J.F. Martin and collaborators (2006) the behaviour of emergy indicators in three agricultural systems is studied: conventional corn production (Zea mays L.) in Kansas, USA, blackberry (Ru-busrubus Watson) in Ohio, USA, and a polyculture rotation system in Chiapas, Mexico [40]. From the analysis of the indicators, it can be concluded that the most sustainable crops require renewable sources of energy, due to the substantial amounts of energy needed for agricultural production.

Energy and heat cogeneration (CHP) processes using biomass and coal are also evaluated, using an energy-focused environmental accounting method based on the embodied solar energy (emergy) [41]. Plants are analysed from the point of view of long-term and large-scale sustainability. Comparing cogeneration and independent production, biomass cogeneration was found to be 3.3 times more efficient from the emergy point of view than independent coal-based production. The emergy expresses how much work the biosphere must do to provide a product or service. Given these results, the biosphere needs to work $77 \%$ less for the cogeneration of biomass compared to the independent production of heat and energy based on coal. So, biomass-fed plants are much more sustainable from an emergy point of view.

Emergy has also been used to compare renewable energy sources with traditional energy sources. An example of this is presented in [42], where a thermal power plant is compared to a photovoltaic power plant. The results show that the thermal plant was more sustainable and efficient than the photovoltaic plant.

A different use of emergy is proposed in [43], where an environmental accounting method was applied to the production of concrete and cement to evaluate its dependence on natural resources, even non-renewable, and heavily relied on external inflows. The authors evaluate the main stages of the production process of this material, the Emergy Investment Ratio is evaluated, and it is presented as a synthetic indicator of sustainability. This type of study reveals the over-exploitation of natural resources and the unsustainability of the current construction system.

\subsubsection{Community Solar Energy Applications}

Solar energy is an inexhaustible source of sustainable energy, so its applicability has been expanded through advances in production techniques. A wide community of scientists has developed, publishing their findings in the different production fields and possible scenarios for this energy. In this community, jobs based on the use of photovoltaic solar energy are concentrated to produce drinking water, in agriculture or the implementation of photovoltaic greenhouses.

This community is made up of 99 documents. It is the fifth community in size, with a contribution of $8.64 \%$ of published documents. This community is related to Environmental sustainability, Sustainability assessment, Sustainable energy solutions and Environmental payback time analysis communities (Figure 7). Figure 15a shows the concentration of the nodes, where there are eight larger nodes, while the rest are medium-sized nodes. The three major nodes are:

- "A review of renewable energy technologies integrated with desalination systems" with 273 cites [44].

- "Energy sustainable greenhouse crop cultivation using photovoltaic technologies" with 20 cites [45].

- "Solar radiation distribution inside a greenhouse with south-oriented photovoltaic roofs and effects on crop productivity" with 102 cites [46]. 


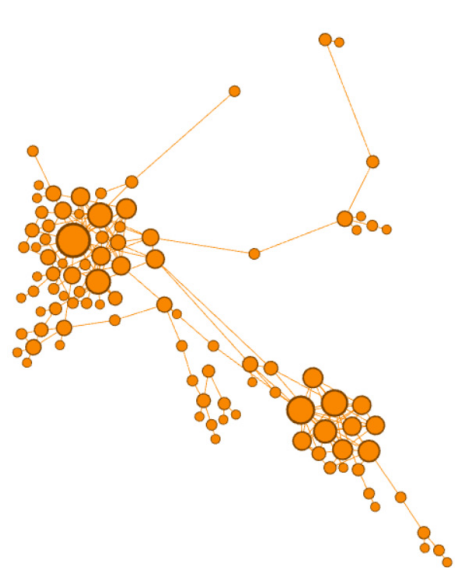

(a)

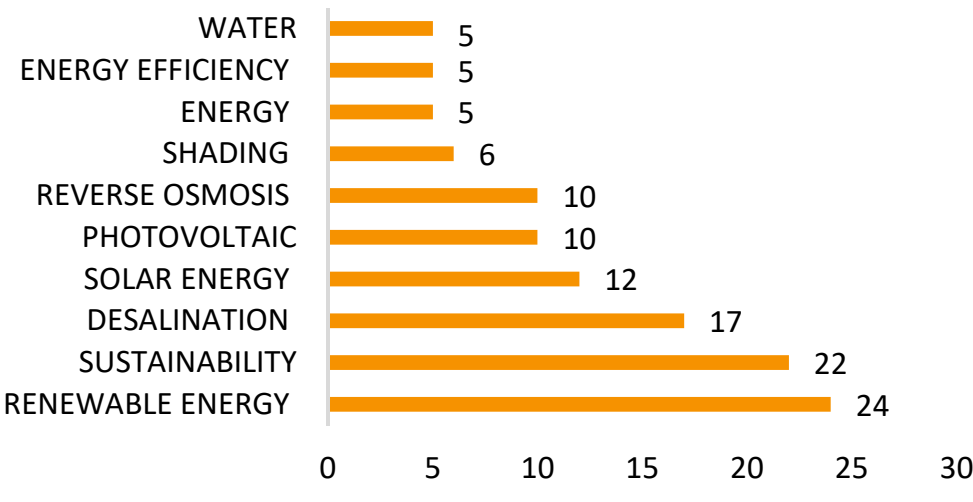

(b)

Figure 15. Solar energy application: (a) Manuscripts published; (b) keywords.

Figure $15 \mathrm{~b}$ represents the 10 most frequent words in this community, representing $23.57 \%$ of the words present in the community and $4.22 \%$ of the total global keywords. The two words with the highest number of repetitions are renewable energy and sustainability, with a frequency of appearance in the community of $4.88 \%$ and $4.47 \%$, respectively. Both words coincide with the most globally important, although in reverse order of importance. In total, $60 \%$ of the words that make up the top 10 of this community are part of the 10 most globally important words, a common trend in most of the communities. It should be noted that the third most repeated word in this community is desalination (3.46\%), a word that is among the 25 most globally frequent and that constitutes the main topic of many publications, as it is one of the most frequent applications of solar energy. Besides, the top 10 keywords of this community are diverse words such as reverse osmosis $(2.03 \%)$, shading $(1.22 \%)$ or water $(1.02 \%)$, which can reflect the variability of applications from the main theme of this community.

In this community, works have been published where solar energy resources are integrated with production systems. An example of this is the integration of solar energy for desalination and water purification. M.A. Eltawil, Z. Zhengming, and L. A. Yuan, L. (2009), global efforts to produce freshwater using renewable energy are reviewed [44]. Desalination is a traditional way of providing fresh water, but in most cases, fossil fuel is used for this, which does not provide environmental sustainability. The analysis of the different renewable sources for this application yields recommendations depending on the place and the renewable energy resources available. Photovoltaic solar energy is recommended for the autonomous use of desalination in remote areas. In places with access to wind resources, wind energy is considered the best option since its cost is lower than photovoltaic solar energy. Where geothermal energy resources predominate, they can be applied at a reasonable cost. From an environmental perspective, work must be done on the elimination of waste products, such as brine and the production of greenhouse gases. Exploring renewable energy solutions can provide sustainable viability. Despite this, the results of the analyses indicate that its real-world penetration is low, despite being a mature technique, so considerable technical improvements must be established.

R. Aroca-Delgado and collaborators in [2] the environmental, economic, and social sustainability of water desalination is evaluated, using the electrodesalination method fed with photovoltaic energy. From an environmental point of view, the use of photovoltaic energy represents a significant reduction in $\mathrm{CO}_{2}$ emissions. Economically, the authors predict a decrease in the cost of photovoltaic installations and an increase in the price of electricity. It is also necessary to consider the increase in local employment in the places where this type of system is installed. Therefore, this method of desalination with photovoltaic energy can be profitable. 
Another combination proposed is the production of electrical energy through photovoltaic capture and agricultural production under a greenhouse [47]. In the photovoltaic greenhouse, $50 \%$ of the greenhouse area is covered with photovoltaic panels, reducing the surface area for capturing solar radiation for agricultural production. Under these conditions, the crop yield decreases concerning the traditional greenhouse, although an income is established to produce electricity. In this study, it is proposed that in the design of the panel installation, the levels of persistent shade should be avoided in the crop, and the crop should also be properly selected. All these recommendations are aimed to ensure that the agrochemical products and the environmental conditions generated in the photovoltaic greenhouse do not reduce agricultural production or affect the long-term maintenance and useful life of the photovoltaic installation. Other subsequent studies support the same experimental results [45]. Yano and Cossu (2019) review photovoltaic greenhouses and confirm that they can reduce traditional non-sustainable energy consumption. This study collects several cases to improve crop-photovoltaic compatibility. This compatibility varies according to combinations of geography, season, crop species and photovoltaic technologies. Another study with a similar theme is [47], where the optimal configurations of the photovoltaic panels on the greenhouse are studied. The detection of strategies to design photovoltaic greenhouses is the main purpose of the research. To achieve the goal, the study considers the selection of species and crop management practices adapted to a persistent and high shade. Suitable crops, crop management techniques and innovations in photovoltaic greenhouses can be identified by characterising the solar distribution.

Emerging technologies in the field of integrating photovoltaic systems in greenhouses are also studied [48]. The electrical performance is compared as a function of the coverage ratio and the type of photovoltaic technology, establishing that the electrical performance increases almost linearly with the coverage index. As a result of the research, a correlation between the growth parameters and the characteristics of the photovoltaic installation has been observed. Finally, the application of new photovoltaic technologies such organic, dye-sensitized and perovskite solar cells has been analysed. Organic solar cells offer many photoactive materials, which allows the spectral features to be adjusted to the characteristics of the crops inside the greenhouse.

\subsubsection{Community Sustainable Energy Optimisation}

Solar energy presents great contributions as a sustainable energy source, and in conjunction with other renewable energy sources, it allows addressing the electric demand in remote places without the need to be connected to the electricity grid. This energy source reduces the environmental impact of the generation stations, although there are safety, health, and environmental barriers. To reduce these obstacles and to achieve the optimization and sustainability of the system, methods for optimizing operations should be established, as well as the planning of the established electrical system.

In this community, applications are investigated where processes are optimized, and the necessary recommendations are made to solve the negative complications associated with this type of system. This community is made up of 94 documents. It is the seventh community in size with a contribution of $8.20 \%$ of published documents. It is related to the communities Sustainability of solar energy in different scenarios, Sustainability assessment, Energy transition and Environmental payback time analysis (Figure 7). Figure 16a shows the concentration of the nodes, where there is a predominance of medium-sized nodes over small ones. The three principal nodes are:

- "A review of Safety, Health and Environmental (SHE) issues of solar energy system" with 99 cites [49].

- "Multi-objective optimum design of hybrid renewable energy system for sustainable energy supply to a green cellular networks" with 1 cite [50].

- "Hybrid off-grid SPV/WTG power system for remote cellular base stations towards green and sustainable cellular networks in South Korea" with 25 cites [51]. 


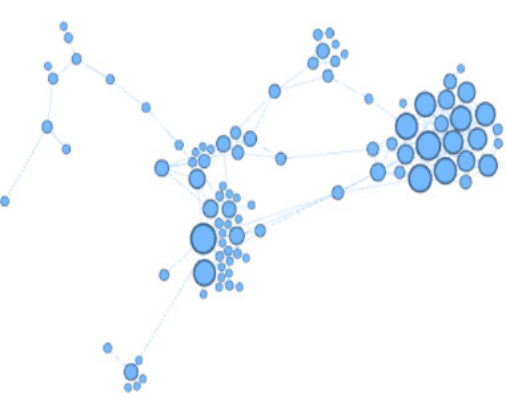

(a)

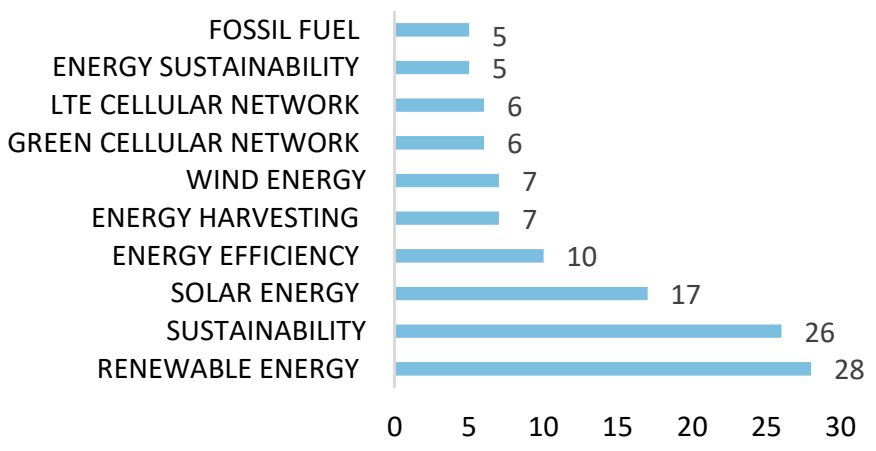

(b)

Figure 16. Sustainable energy optimization: (a) Manuscripts published; (b) keywords.

Figure $16 \mathrm{~b}$ represents the top 10 of the most repeated keywords in this community, representing $24.89 \%$ of the total community $(4.26 \%$ of the total). As in the previous community, the two most important keywords coincide with the most important words at a global level, although the order of appearance is reversed. They are renewable energy and sustainability, with $5.96 \%$ and $5.53 \%$ of the total words of this community, respectively. The third word with the highest appearance is solar energy $(3.62 \%)$, which coincides with the third most globally repeated word. It should be noted that only $40 \%$ of the most important keywords in this community are present among the 10 most globally important. The rest of the keywords in the top 10 have a repetition frequency almost five times lower than the most important word, considering concepts related to several types of sustainable energies, such as wind energy $(1.49 \%)$, green cell network $(1.28 \%)$ or energy sustainability $(1.06 \%)$.

The scientific community is aware of the importance of improving the production of sustainable alternative energies so that $\mathrm{CO}_{2}$ emissions and the greenhouse effect are reduced. To achieve this goal, investigations in which the disadvantages of solar energy are reviewed are being carried out [49], from the perspective of safety, health, and environment. Among its findings, in order to reduce the adverse ecological effects of this energy source, various measures or actions can be established, the most important ones are the improvement of the efficiency of photovoltaic modules for the use of covered land in the facilities, the reduction in the use of hazardous materials in manufacturing, or the use of other alternative materials that are more ecological, with longer useful life and less silicon content per module. Attention should also be paid to the recycling process, by collecting waste from facilities, recycling at specialized locations, and treating waste to avoid contamination.

Numerous publications that appear in the literature are related to the optimization of energy resources from different perspectives. As society advances, novel solutions to everyday applications emerge, focused on solving the electricity supply, or optimizing the system so that it is viable from an energetic, technical, economic, and environmental perspective. An example of this are publications [51] and [50], where it is investigated how to provide energy support to telecommunications networks. These facilities are spread throughout the world, consume a large amount of energy, and require improving energy sustainability and reducing cost. Alsharif and Kim (2017) propose a solar photovoltaic hybrid energy supply system and a wind turbine generator [51]. The purpose of this system is to supply energy to the base station located in a remote place and disconnected from the South Korean grid. For this, the system is optimized, while the energy efficiency, the economic cost and greenhouse gas emissions are minimized. The study compares the economic and environmental viability of the developed system to a diesel generator system. The authors concluded that the best solution is the hybrid generator. Another proposal is a hybrid system of photovoltaic solar energy and one generated by biomass, developed by Hossain and collaborators (2020) [50]. The result of the simulations carried out is encouraging, since the energy system and the base station can provide service without 
reducing the quality of communications, using a battery bank as backup power. The results were compared with other alternative systems such as photovoltaic, with the hybrid system showing the best results in the simulations.

Establishing coverage of mobile networks in rural areas is not an easy task, since in most of the cases they are areas that lack an electricity network. M.H. Alsharif and collaborators in [52], the feasibility of integrating a solar power system with a diesel generator to supply power to remote base stations at off-grid sites in Malaysia is examined. The indicators used are energy performance analysis, economic analysis, and greenhouse gas emissions. The established conclusions indicate that in regions such as Malaysia, where the solar incidence is considerable, this type of hybrid generator manages to reduce the emission of greenhouse gases and the cost of the system operation. Hybrid power stations have also been analysed in Bangladesh, composed of solar photovoltaic energy, wind energy and biomass [53]. Through an optimal distribution of energy sources, the system has enough potential to supply its energy demand without interruptions in time. In line with this research, in [54], the feasibility and effectiveness of a hybrid generation system based on a photovoltaic system and a biomass resource generator in stations located outside the Bangladeshi grid is exposed. For the feasibility analysis, simulation based on the Hybrid Optimization Model for Electric Renewables (HOMER) is used. Performance is analysed using Matlab-based Monte Carlo simulations. The results of the research reveal that the proposed system is ecologically and technically viable, which is why it is a sustainable solution to the problem posed.

\subsubsection{Community Energy Transition}

In the last two decades, profound changes have been experienced in technical, social, economic, and environmental aspects, derived from the energy transition. This community includes publications which have as their main topic the energy transition, the existing changes and how they are insufficient to manage future environmental and social challenges.

This community is made up of 90 documents. It is the eighth community in size with a contribution of $7.85 \%$ of published documents. This community maintains relations with the following communities: Sustainable energy optimisation, Sustainability of solar energy in different scenarios and Environmental payback time analysis mainly (Figure 7). Figure 17a shows the concentration of the nodes, medium-sized nodes predominate. This indicates that it is a current topic. The three principal nodes are:

- "Structural changes of global power generation capacity towards sustainability and the risk of stranded investments supported by a sustainability indicator" with 92 cites [55].

- "How to achieve a 100\% RES electricity supply for Portugal?" with 132 cites [56].

- "The features of sustainable Solar Hydroelectric Power Plant" with 40 cites [57].

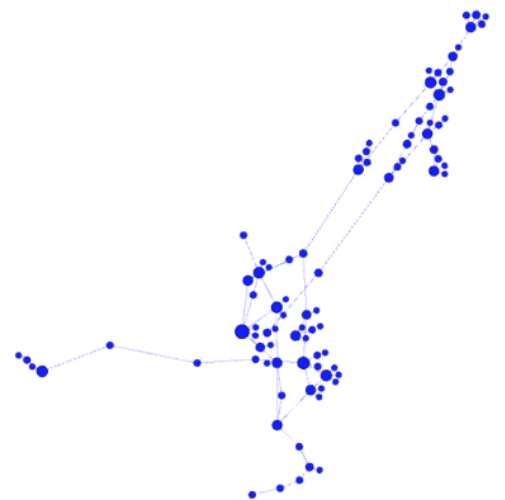

(a)

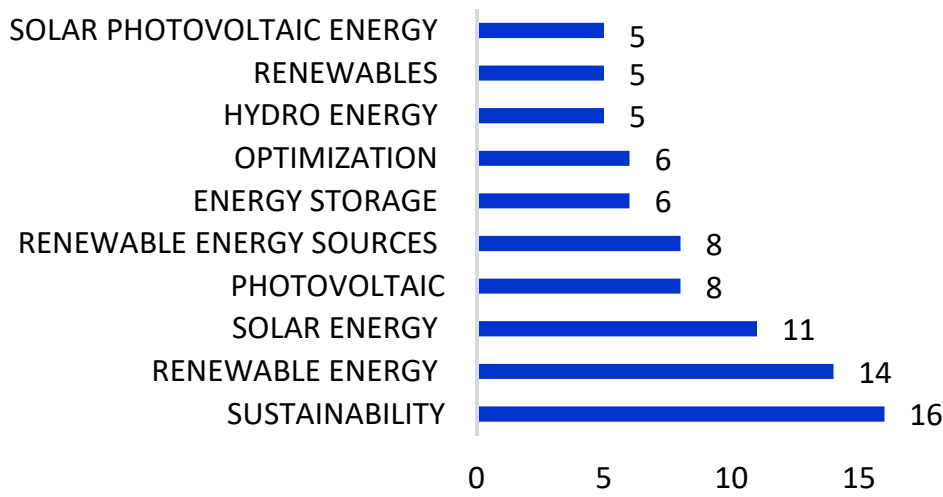

(b)

Figure 17. Energy transition: (a) Manuscripts published; (b) keywords. 
Figure $17 \mathrm{~b}$ shows the top ten words in the community. These words represent $16.18 \%$ of the keywords in the community and 3.06\% of the total number of keywords. Despite being one of the smallest communities, it has a higher number of keywords than the previous largest community. This is due to the variability and topicality of the subjects covered. Like in the smaller communities, the number of top 10 community keywords present in the top 10 of the keywords is only four. Of these four words, the first three coincide in order of appearance with the most important words at the global level. These words are sustainability $(3.08 \%)$, renewable energy $(2.70 \%)$ and solar energy $(2.12 \%)$. The fourth word, photovoltaic $(1.54 \%)$, is the fifth most globally frequent word. The rest of the words that make up the top 10 of the community have a low frequency of repetition and they are mostly in the top 50 globally, such as renewable energy source (1.54\%), optimization $(1.16 \%)$ and renewables $(0.96 \%)$. A special case is the word hydroenergy which is located after position 100 in repetition importance and represents $0.22 \%$ of the total number of keywords.

There are enough renewable energy resources in the world to meet present and future energy needs, although some of these resources are currently not economically or technically viable. Modernizing power plants is necessary to achieve a sustainable future. Z. Glasnovic and J. Margeta (2009), a Solar Hydroelectric Plant that uses solar energy as the only means to produce solar and hydraulic energy is presented [57]. This system was sized to establish the electricity supply for the island of Vis in Croatia, where its technical and sustainable viability was proven.

In this community, the transition process towards fully sustainable energy systems is established in different countries. An example is presented in [56], the simulation of the planning of the Portuguese energy system and the technical solutions to achieve $100 \%$ electricity production by renewable means. It proposes to reduce consumption by making more efficient use of energy and betting on hydro and wind energy. Applying energy efficiency measures could accelerate and facilitate the conversion process of the energy industry in this country.

The trend usually found in most countries is an increase in renewable energy, coal, and gas power plants, as well as a decrease in new nuclear power plants [55]. Reaching the goal of zero emissions in 2050 goes through a conversion of the energy sector towards $100 \%$ renewable. An analysis of the operational useful life of traditional power plants (40 to 34 years), nuclear power plants (28 years) and hydroelectric plants is carried out, in which the lifespan can be extended to more than 100 years with renovations. Solar and wind energy production can extend their useful life, taking advantage of technological advances in solar panels or wind turbines. While the production of energy based on coal has its days numbered, those based on gas can be redirected to renewables through biogas, which is why the oil companies are not affected to a great extent. J. Farfan and C. Breyer (2017) in [55], the energy system transition model is also exposed and analysed. According to this model, the average cost of energy throughout the planet will gradually decrease during the transition process, with $95 \%$ decarbonisation being possible by 2040 . The model predicts that in 2050 around $69 \%$ of electricity generation will come from photovoltaic generators. This will be possible if the cost of photovoltaic systems and batteries continues to decline.

The exploitation of solar energy is essential to carry out the energy transition. A. Kasaeian and collaborators (2020) in [58], the use of various sources of solar energy in polygeneration systems is studied. These systems enable high efficiency and provide multiple useful energy outputs, including heating, cooling, electricity, hydrogen, and fresh water. In line with this research, Dominković and collaborators (2016) presents the transition steps to achieve a fully renewable energy system by 2050 in Southeast Europe with a zero-carbon footprint [59]. In this publication, the authors present an innovative characteristic: the sustainable use of biomass and a combination of renewable energies where none exceed $30 \%$ participation. This transition, in addition to the clear environmental benefit, will be a driver of economic growth. Completing this transition is not a simple task, coordinated measures must be taken on a large scale to implement it. 


\subsubsection{Community Energy and Sustainable Scenarios}

There is a long way to go towards a sustainable energy system. The application of this transformation is increasing, considering that renewable energy facilities improve the system, considering the present climate change. This community investigates the new perspectives of changes in traditional applications, to redesign more sustainable systems, using renewable energy.

This community is made up of 71 documents. It is a small community in size with a contribution of $6.20 \%$ of published documents. This community maintains a relationship with the Sustainable energy solutions, Sustainability of solar energy in different scenarios and Sustainability assessment communities mainly (Figure 7). Figure 18a shows the concentration of the nodes, the predominance being medium nodes, although some larger ones can be identified. The three main nodes are:

- "Life cycle assessment of a parabolic trough concentrating solar power plant and the impacts of key design alternatives" with 133 cites [60].

- "A review on development of solar drying applications" with 95 cites [61].

- "A review on energy scenario and sustainable energy in Malaysia" with 249 cites [3].

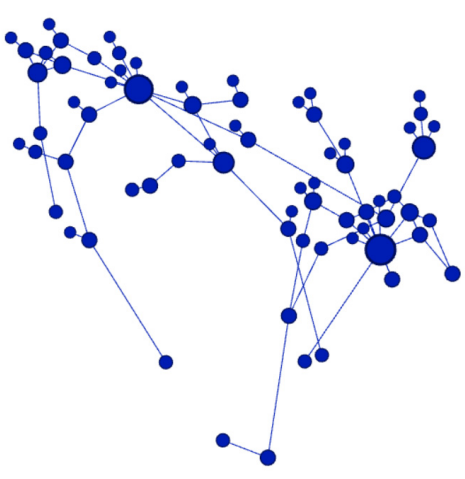

(a)

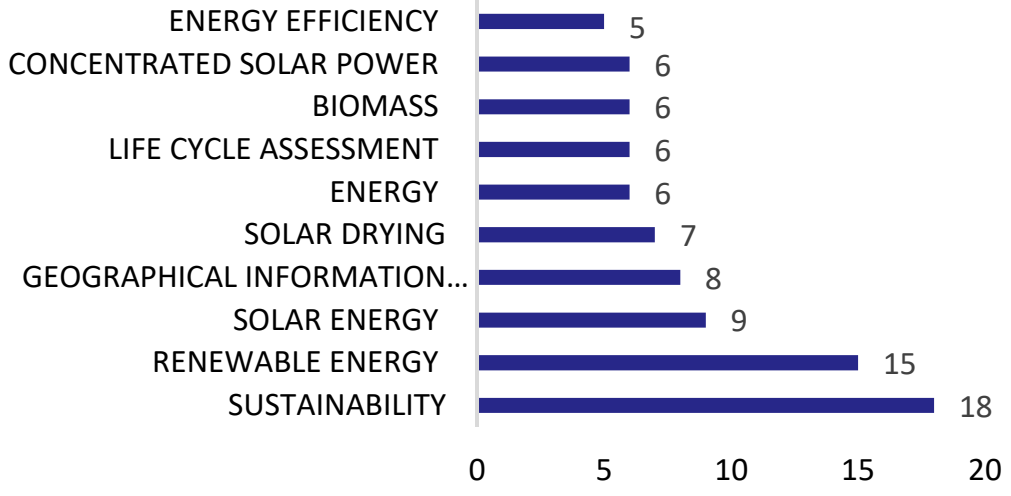

(b)

Figure 18. Energy and sustainable scenarios: (a) Manuscripts published; (b) keywords.

This community is the smallest and its keywords are $13.51 \%$ of the total. The representation of the 10 most important keywords of this community is shown in Figure 18b and they represent $23.18 \%$ of the total of its keywords. The keyword with the highest number of repetitions coincides with the most globally frequent word, sustainability, which represents $4.85 \%$ of the total words in the community. As in most communities, $60 \%$ of the keywords in the top 10 matches the top 10 of global keywords. An example of this is the words renewable energy $(4.04 \%)$, solar energy $(2.43 \%)$ or life cycle assessment $(1.62 \%)$. The rest of the words that make up the top 10 are words of a different nature, with an exceptionally low frequency, as occurs with geographical information $(2.16 \%)$, solar drying $(1.89 \%)$ or biomass $(1.62 \%)$.

The world is going towards a necessary transformation to sustainable systems due to climate change. Burkhardt et al. (2011) analyse the design of a parabolic cylindrical collector (CSP) concentrating solar power installation, located in Daggett (USA). This analysis is carried out from the point of view of water consumption and $\mathrm{CO} 2$ emissions [60]. The plant emits $26 \mathrm{~g}$ of $\mathrm{CO}_{2}$ eq per $\mathrm{kWh}$, consumes $4,7 \mathrm{~L} / \mathrm{kWh}$ of water and demands $0.40 \mathrm{MJ} \mathrm{eq} / \mathrm{kWh}$ of energy, with an energy recovery time of approximately 1 year. The greenhouse gas emission rate is lower than that established by traditional production, $46 \%$, and takes place in the manufacturing phase. The energy storage systems used in these facilities depend on the salts used. In this work, they evaluate the use of synthetic or natural salts as thermocline for the dry cooling system. In the life cycle of the thermocline, greenhouse gas 
emissions are reduced, compared to synthetic salts (52\% increase), and water consumption is also reduced.

Another example of an energy challenge occurs in Malaysia [3]. Despite having many renewable resources in biomass through palm oil, it has energy difficulties and must strive to achieve greater efficiency in the conversion, transmission and use of energy, to reconversion towards energy sustainability. Ong and collaborators (2011) affirm that Malaysia is not prepared to adopt the transformation towards the near future of renewable energy, requiring an institutional and social effort to promote the use of these energies.

The industry also requires a reconversion to optimize energy consumption. In the case of the food, dairy, textile, sewage sludge, wood and cement industries, a solar drying process is carried out [61]. This process improves product quality, reduces greenhouse gas and $\mathrm{CO}_{2}$ emissions, and allows economic recovery in the short-medium term. The study shows that the payback period ranges from 1 to 10 years, which implies economic viability and environmental improvements since its implementation. In line with this study, Ndukwu et al. (2017) in [62] a natural convection solar dryer (NCSDR) for drying red chilli is analysed. This study concludes that using sodium sulphate decahydrate as thermal energy storage increases the efficiency of the dryer and reduces its carbon footprint compared to those that use diesel.

Currently, research efforts and economic investment by governments are needed for the development of sustainable technology. Baral et al. (2015), an experiment and thermo-economic analysis of a small-scale organic Rankine cycle (ORC) is carried out [63]. This technology consists of a renewable energy generation system, it can be implemented in rural areas without access to the electricity grid of developing countries and it was developed for the atmospheric conditions of Busan (South Korea). The results obtained show that the system is sustainable, although with a payback period of 19 years. This technology is only employed in rural areas of developing countries because of the long payback period. These places often lack electricity to light homes.

Many of the energy generation systems from renewable sources depend on fossil fuels for their proper operation. An example of this is concentrating solar power (CSP) plants based on parabolic troughs, which requires the use of auxiliary fuel to start up and increase power generation. Corona, San Miguel and Cerrajero (2014) the impact on the sustainability of different load configurations of natural gas as an auxiliary fuel is analysed, being essential to size this impact in hybrid systems, to achieve the sustainability objectives [64].

\section{Conclusions}

This work has analysed the research collected in the publications of sustainability associated with the topic of solar energy, from 1995 to 2020. In the publications studied, a total of 2746 keywords were obtained. The keyword with the highest appearance is Sustainability, with 286 repetitions (10.41\%). The next most important words according to the number of repetitions are Renewable energy $(6.5 \%)$ and Solar energy (4.6\%). The 10 most globally repeated words are among the 10 most repeated of each community separately and together they constitute $37 \%$ of the total of the existing words. All of them are related to the theme of sustainability, renewable energy and concepts related to solar energy. The rest of the words appear on a small number of occasions, so their size compared to the rest is small and they represent less than $1 \%$ of the total of the keywords, as it happens with Environmental impact (0.9\%).

There are 11,848 authors from 131 countries researching the subject. The countries with the highest contribution of researchers are the United States, China, Italy, and India. The 20 authors with the highest $H$ index present values higher than 100. The author with the highest $\mathrm{H}$ index is from Switzerland, the second, third and fourth are from the United States.

Most of the publications are articles and the main language is English. The subject matter studied in the different communities is published in 1146 different magazines. 
The most frequent are Renewable and Sustainable Energy Review, Journal of Cleaner Production and Applied Energy. Most of these publications are established in journals with a high impact factor, with a value greater than 2.5 in most cases.

After the review process using keywords, 4260 documents were obtained that presented 2195 relationships. This information was treated later with bibliometric techniques and filtered until the 1146 documents with 1872 relationships were established. These documents are distributed in nine communities according to the subject matter and the collaborations present between the authors. The largest community is Sustainability assessment (15.27\% of the documents), followed by Sustainable energy solutions $(14.40 \%)$ and Environmental payback time analysis (14.14\%). The next two communities are slightly smaller in size, $13.18 \%$ and $12.13 \%$, being the Sustainability of solar energy in different scenarios and Environmental sustainability communities, respectively. The rest of the communities are smaller than $9 \%$, Solar energy applications (8.64\%) and Sustainable energy optimization $(8.20 \%)$ are similar in size. The smallest communities are Energy transition (7.87\%) and Energy and sustainable scenarios (6.20\%).

The Sustainability assessment community is a highly active community due to the lack of standards in sustainability assessment indicators. This community has strong relationships with the Sustainable energy solutions community, which aims to provide sustainable solutions for solving the inconveniences that the use of renewable energies presents. It is also related to the community Environmental payback time analysis, in which the life cycle indicator is applied to assess the environmental impact of the use of these energies. These strong relationships may be because the sustainability assessment indicators must consider energy and environmental aspects, such as those discussed in the Sustainable energy solutions and Environmental payback time analysis communities, respectively. There is a scientific community where emergy has been considered as a reference indicator of environmental sustainability. It is an active community due to the unification of the application of the concept and its breadth, where economic, social, environmental, and efficient aspects are considered.

Two communities strongly related to solar energy have been established, from the point of view of its sustainability and its possible applications. These communities are the Sustainability of solar energy in different scenarios and Solar energy applications. It should be considered that the most applicable energy at present is photovoltaic energy, a fact that is expected to increase in the future, although it is not the only one. Although it is a mature technique, the improvement of techniques is still required to achieve greater efficiencies soon. The Sustainable energy optimization community aims to establish the optimization of remote energy systems, where energy needs are paramount. Therefore, the optimization of these systems is mandatory to achieve their applicability, as there are no other alternatives available. Currently, there are remote areas without basic energy resources, so this issue continues to be actively investigated and is considered a social, economic, and environmental challenge. This requires the active collaboration of the scientific community and the political and social support of the governments, which should contribute to the economic endowment of the installation and maintenance of these energy systems.

The Energy transition community is small, but it indicates the concern of the scientific community in the application of energy changes and putting them into operation, considering technical, social, economic, and environmental aspects. The Energy and sustainable scenarios community considered one aspect of Sustainable energy solutions, focuses on the implication of climate change and its relationship with sustainable energies. It is the smallest community, and it considers a topic that is highly debated in different fields at present and that will raise new future research.

The analysis of the topics studied in this document proposes that energy sustainability should not be treated as an individual approach, since socioeconomic, technological, and environmental characteristics must be considered. The resources available in the start-up of the system should be considered in order to be efficient in the long term. To facilitate 
the implementation in this interactive framework, the mindset must be changed, and the energy transformation plan. A science-engineering approach should be considered that encompasses research, education, and efficient practice of the renewal of energy production systems, where the domain of renewable energies is properly implemented. Environmental awareness of users and governors is required, it being in the hands of the governments to facilitate such policies for the energy transformation and plan the operations for the best use of the renewable energy resources available in each area. They must provide infrastructures that allow the long-term maintenance of the investments developed. The next generation of scientists and engineers must also be adequately trained in environmental awareness, to solve the pending technical challenges, to make better use of natural energy resources that are still unexploited or with low applicability. In this work, real installations, contexts, and present and future scenarios of the energy system have been analysed, always considering that the trend must be directed towards global sustainability. The interrelationships between the industrial, academic, and political sectors are necessary for the growth and insertion of recent technologies, allowing a consolidated knowledge base of innovation systems in the proliferation of sustainable solar energies.

Many of the manuscripts studied indicated that polygeneration systems powered by (i) solar energy with parabolic trough collectors; (ii) concentration photo-voltaic thermal energy and (iii) solar tower, can be sustainable and viable systems for their application in future energy products, fundamental for the energy transition. The trend that is usually found in most countries is an increase in renewable energy. The study of past trends can help to plan the future environmental sustainability, while it is directly related to the well-being of society. Changes were observed in the energy system in society and gaps were revealed for future research and investment in renewable energy.

Author Contributions: N.N. and R.M.G. formed and revised the manuscript; R.M.G. and A.A. developed the figures and tables; A.A. contributed to the search of dates and the realization of the maps; N.N., R.M.G. and J.M.C. wrote the manuscript; N.N. and R.M.G. checked the whole manuscript. All authors have read and agreed to the published version of the manuscript.

Funding: This research received no external funding.

Institutional Review Board Statement: Not applicable.

Informed Consent Statement: Not applicable.

Data Availability Statement: The data is published in the Scopus database which collects information on publications.

Acknowledgments: Under I+D+I Project UAL18-TIC-A025-A, University of Almeria, the Ministry of Economy, Knowledge, Business and University, and the European Regional Development Fund (FEDER); Andalusian Regional Government through the Electronics, Communications and Telemedicine TIC019 Research Group of the University of Almeria, Spain; and in part by the European Union FEDER Program and CIAMBITAL Group.

Conflicts of Interest: The authors declare no conflict of interest.

\section{References}

1. Fernandez-Gonzalez, C.; Dominguez-Ramos, A.; Ibañez, R.; Irabien, A. Sustainability Assessment of Electrodialysis Powered by Photovoltaic Solar Energy for Freshwater Production. Renew. Sustain. Energy Rev. 2015, 47, 604-615. [CrossRef]

2. Aroca-Delgado, R.; Pérez-Alonso, J.; Callejón-Ferre, Á.J.; Velázquez-Martí, B. Compatibility between Crops and Solar Panels: An Overview from Shading Systems. Sustainability 2018, 10, 743. [CrossRef]

3. Ong, H.C.; Mahlia, T.M.I.; Masjuki, H.H. A Review on Energy Scenario and Sustainable Energy in Malaysia. Renew. Sustain. Energy Rev. 2011, 15, 639-647. [CrossRef]

4. Montoya, F.G.; Alcayde, A.; Baños, R.; Manzano-Agugliaro, F. A Fast Method for Identifying Worldwide Scientific Collaborations Using the Scopus Database. Telemat. Inform. 2018, 35, 168-185. [CrossRef]

5. Mongeon, P.; Paul-Hus, A. The Journal Coverage of Web of Science and Scopus: A Comparative Analysis. Scientometrics 2016, 106, 213-228. [CrossRef]

6. Bastian, M.; Heymann, S.; Jacomy, M. Gephi: An Open Source Software for Exploring and Manipulating Networks. In Proceedings of the Third International ICWSM Conference, San Jose, CA, USA, 17-20 May 2009; pp. 361-362. [CrossRef] 
7. Novas, N.; Alcayde, A.; Robalo, I.; Manzano-Agugliaro, F.; Montoya, F.G. Energies and Its Worldwide Research. Energies 2020, 13, 6700. [CrossRef]

8. García, R.M.; Novas, N.; Alcayde, A.; Khaled, D.E.; Fernández-Ros, M.; Gazquez, J.A. Progress in the Knowledge, Application and Influence of Extremely Low Frequency Signals. Appl. Sci. 2020, 10, 3494. [CrossRef]

9. O'Regan, B.; Grätzel, M. A Low-Cost, High-Efficiency Solar Cell Based on Dye-Sensitized Colloidal TiO2 Films. Nature 1991, 353, 737-740. [CrossRef]

10. Grätzel, M. Photoelectrochemical Cells Michael. Nature 2001, 414, 338-344. [CrossRef]

11. Love, J.C.; Estroff, L.A.; Kriebel, J.K.; Nuzzo, R.G.; Whitesides, G.M. Self-Assembled Monolayers of Thiolates on Metals as a Form of Nanotechnology. Chem. Rev. 2005, 105, 1103-1170. [CrossRef] [PubMed]

12. Wang, Z.L.; Song, J. Piezoelectric Nanogenerators Based on Zinc Oxide Nanowire Arrays. Science 2006, 312, 242-246. [CrossRef]

13. Santoyo-Castelazo, E.; Azapagic, A. Sustainability Assessment of Energy Systems: Integrating Environmental, Economic and Social Aspects. J. Clean. Prod. 2014, 80, 119-138. [CrossRef]

14. Mainali, B.; Silveira, S. Using a Sustainability Index to Assess Energy Technologies for Rural Electrification. Renew. Sustain. Energy Rev. 2015, 41, 1351-1365. [CrossRef]

15. Afgan, N.H.; Carvalho, M.G.; Hovanov, N.V. Energy System Assessment with Sustainability Indicators. Energy Policy 2000, 28, 603-612. [CrossRef]

16. Streimikiene, D.; Balezentis, T.; Krisciukaitien, I.; Balezentis, A. Prioritizing Sustainable Electricity Production Technologies: MCDM Approach. Renew. Sustain. Energy Rev. 2012, 16, 3302-3311. [CrossRef]

17. Ahmad, S.; Tahar, R.M. Selection of Renewable Energy Sources for Sustainable Development of Electricity Generation System Using Analytic Hierarchy Process: A Case of Malaysia. Renew. Energy 2014, 63, 458-466. [CrossRef]

18. Dincer, I.; Acar, C. A Review on Clean Energy Solutions for Better Sustainability. Int. J. Energy Res. 2016, 39, 585-606. [CrossRef]

19. Hepbasli, A. A Key Review on Exergetic Analysis and Assessment of Renewable Energy Resources for a Sustainable Future. Renew. Sustain. Energy Rev. 2008, 12, 593-661. [CrossRef]

20. Caliskan, H. Energy, Exergy, Environmental, Enviroeconomic, Exergoenvironmental (EXEN) and Exergoenviroeconomic (EXENEC) Analyses of Solar Collectors. Renew. Sustain. Energy Rev. 2017, 69, 488-492. [CrossRef]

21. Hepbasli, A. Modeling of Sectoral Energy and Exergy Utilization. Energy Sources 2005, 27, 903-912. [CrossRef]

22. Hepbasli, A. Low Exergy (LowEx) Heating and Cooling Systems for Sustainable Buildings and Societies. Renew. Sustain. Energy Rev. 2012, 16, 73-104. [CrossRef]

23. Dincer, I.; Acar, C. Review and Evaluation of Hydrogen Production Methods for Better Sustainability. Int. J. Hydrog. Energy 2014, 40, 11094-11111. [CrossRef]

24. Acar, C.; Dincer, I.; Naterer, G.F. Review of Photocatalytic Water-Splitting Methods for Sustainable Hydrogen Production. Int. J. Energy Res. 2016, 40, 1449-1473. [CrossRef]

25. Peng, J.; Lu, L.; Yang, H. Review on Life Cycle Assessment of Energy Payback and Greenhouse Gas Emission of Solar Photovoltaic Systems. Renew. Sustain. Energy Rev. 2013, 19, 255-274. [CrossRef]

26. Onat, N.; Bayar, H. The Sustainability Indicators of Power Production Systems. Renew. Sustain. Energy Rev. 2010, 14, 3108-3115. [CrossRef]

27. Lu, L.; Yang, H.X. Environmental Payback Time Analysis of a Roof-Mounted Building-Integrated Photovoltaic (BIPV) System in Hong Kong. Appl. Energy 2010, 87, 3625-3631. [CrossRef]

28. Cucchiella, F.; D'Adamo, I.; Lenny Koh, S.C. Environmental and Economic Analysis of Building Integrated Photovoltaic Systems in Italian Regions. J. Clean. Prod. 2015, 98, 241-252. [CrossRef]

29. Little, J.C.; Hester, E.T.; Elsawah, S.; Filz, G.M.; Sandu, A.; Carey, C.C.; Iwanaga, T.; Jakeman, A.J. A Tiered, System-of-Systems Modeling Framework for Resolving Complex Socio-Environmental Policy Issues. Environ. Model. Softw. 2019, 112, 82-94. [CrossRef]

30. Koçak, B.; Fernandez, A.I.; Paksoy, H. Review on Sensible Thermal Energy Storage for Industrial Solar Applications and Sustainability Aspects. Sol. Energy 2020, 209, 135-169. [CrossRef]

31. Feron, S. Sustainability of Off-Grid Photovoltaic Systems for Rural Electrification in Developing Countries: A Review. Sustainability 2016, 8, 1326. [CrossRef]

32. Brent, A.C.; Rogers, D.E. Renewable Rural Electrification: Sustainability Assessment of Mini-Hybrid off-Grid Technological Systems in the African Context. Renew. Energy 2010, 35, 257-265. [CrossRef]

33. Hong, G.W.; Abe, N. Sustainability Assessment of Renewable Energy Projects for Off-Grid Rural Electrification: The Pangan-an Island Case in the Philippines. Renew. Sustain. Energy Rev. 2012, 16, 54-64. [CrossRef]

34. Ulsrud, K.; Winther, T.; Palit, D.; Rohracher, H. Village-Level Solar Power in Africa: Accelerating Access to Electricity Services through a Socio-Technical Design in Kenya. Energy Res. Soc. Sci. 2015, 5, 34-44. [CrossRef]

35. Amran, Y.H.A.; Amran, Y.H.M.; Alyousef, R.; Alabduljabbar, H. Renewable and Sustainable Energy Production in Saudi Arabia According to Saudi Vision 2030; Current Status and Future Prospects. J. Clean. Prod. 2020, 247, 119602. [CrossRef]

36. Dauenhauer, P.M.; Frame, D.; Eales, A.; Strachan, S.; Galloway, S.; Buckland, H. Sustainability Evaluation of Community-Based, Solar Photovoltaic Projects in Malawi. Energy Sustain. Soc. 2020, 10. [CrossRef]

37. Odum, H.T. Environmental Accounting: EMERGY and Environmental Decision Making. Choice Rev. Online 1996, $34,0412$. [CrossRef] 
38. Ulgiati, S.; Brown, M.T. Monitoring Patterns of Sustainability in Natural and Man-Made Ecosystems. Ecol. Modell. 1998, 108, 23-36. [CrossRef]

39. Yang, Q.; Chen, G.Q.; Liao, S.; Zhao, Y.H.; Peng, H.W.; Chen, H.P. Environmental Sustainability of Wind Power: An Emergy Analysis of a Chinese Wind Farm. Renew. Sustain. Energy Rev. 2013, 25, 229-239. [CrossRef]

40. Martin, J.F.; Diemont, S.A.W.; Powell, E.; Stanton, M.; Levy-Tacher, S. Emergy Evaluation of the Performance and Sustainability of Three Agricultural Systems with Different Scales and Management. Agric. Ecosyst. Environ. 2006, 115, 128-140. [CrossRef]

41. Sha, S.; Hurme, M. Emergy Evaluation of Combined Heat and Power Plant Processes. Appl. Therm. Eng. 2012, 43, 67-74. [CrossRef]

42. Paoli, C.; Vassallo, P.; Fabiano, M. Solar Power: An Approach to Transformity Evaluation. Ecol. Eng. 2008, 34, 191-206. [CrossRef]

43. Pulselli, R.M.; Simoncini, E.; Ridolfi, R.; Bastianoni, S. Specific Emergy of Cement and Concrete: An Energy-Based Appraisal of Building Materials and Their Transport. Ecol. Indic. 2008, 8, 647-656. [CrossRef]

44. Eltawil, M.A.; Zhengming, Z.; Yuan, L. A Review of Renewable Energy Technologies Integrated with Desalination Systems. Renew. Sustain. Energy Rev. 2009, 13, 2245-2262. [CrossRef]

45. Yano, A.; Cossu, M. Energy Sustainable Greenhouse Crop Cultivation Using Photovoltaic Technologies. Renew. Sustain. Energy Rev. 2019, 109, 116-137. [CrossRef]

46. Cossu, M.; Murgia, L.; Ledda, L.; Deligios, P.A.; Sirigu, A.; Chessa, F.; Pazzona, A. Solar Radiation Distribution inside a Greenhouse with South-Oriented Photovoltaic Roofs and Effects on Crop Productivity. Appl. Energy 2014, 133, 89-100. [CrossRef]

47. Cossu, M.; Cossu, A.; Deligios, P.A.; Ledda, L.; Li, Z.; Fatnassi, H.; Poncet, C.; Yano, A. Assessment and Comparison of the Solar Radiation Distribution inside the Main Commercial Photovoltaic Greenhouse Types in Europe. Renew. Sustain. Energy Rev. 2018, 94, 822-834. [CrossRef]

48. La Notte, L.; Giordano, L.; Calabrò, E.; Bedini, R.; Colla, G.; Puglisi, G.; Reale, A. Hybrid and Organic Photovoltaics for Greenhouse Applications. Appl. Energy 2020, 278. [CrossRef]

49. Aman, M.M.; Solangi, K.H.; Hossain, M.S.; Badarudin, A.; Jasmon, G.B.; Mokhlis, H.; Bakar, A.H.A.; Kazi, S.N. A Review of Safety, Health and Environmental (SHE) Issues of Solar Energy System. Renew. Sustain. Energy Rev. 2015, 41, 1190-1204. [CrossRef]

50. Hossain, M.S.; Jahid, A.; Islam, K.Z.; Alsharif, M.H.; Rahman, M.F. Multi-Objective Optimum Design of Hybrid Renewable Energy System for Sustainable Energy Supply to a Green Cellular Networks. Sustainability 2020, 12, 3536. [CrossRef]

51. Alsharif, M.H.; Kim, J. Hybrid Off-Grid SPV/WTG Power System for Remote Cellular Base Stations towards Green and Sustainable Cellular Networks in South Korea. Energies 2017, 10, 9. [CrossRef]

52. Alsharif, M.H.; Nordin, R.; Ismail, M. Energy Optimisation of Hybrid Off-Grid System for Remote Telecommunication Base Station Deployment in Malaysia. Eurasip J. Wirel. Commun. Netw. 2015, 2015, 1-15. [CrossRef]

53. Hossain, M.S.; Islam, K.Z.; Jahid, A.; Rahman, K.M.; Ahmed, S.; Alsharif, M.H. Renewable Energy-Aware Sustainable Cellular Networks with Load Balancing and Energy-Sharing Technique. Sustainability 2020, 12, 9340. [CrossRef]

54. Hossain, M.S.; Jahid, A.; Islam, K.Z.; Rahman, M.F. Solar PV and Biomass Resources-Based Sustainable Energy Supply for Off-Grid Cellular Base Stations. IEEE Access 2020, 8, 53817-53840. [CrossRef]

55. Farfan, J.; Breyer, C. Structural Changes of Global Power Generation Capacity towards Sustainability and the Risk of Stranded Investments Supported by a Sustainability Indicator. J. Clean. Prod. 2017, 141, 370-384. [CrossRef]

56. Krajačić, G.; Duić, N.; Carvalho, M. How to Achieve a 100\% RES Electricity Supply for Portugal? Appl. Energy 2011, 88, 508-517. [CrossRef]

57. Glasnovic, Z.; Margeta, J. The Features of Sustainable Solar Hydroelectric Power Plant. Renew. Energy 2009, $34,1742-1751$. [CrossRef]

58. Kasaeian, A.; Bellos, E.; Shamaeizadeh, A.; Tzivanidis, C. Solar-Driven Polygeneration Systems: Recent Progress and Outlook. Appl. Energy 2020, 264, 114764. [CrossRef]

59. Dominković, D.F.; Bačeković, I.; Ćosić, B.; Krajačić, G.; Pukšec, T.; Duić, N.; Markovska, N. Zero Carbon Energy System of South East Europe in 2050. Appl. Energy 2016, 184, 1517-1528. [CrossRef]

60. Burkhardt, J.J.; Heath, G.A.; Turchi, C.S. Life Cycle Assessment of a Parabolic Trough Concentrating Solar Power Plant and the Impacts of Key Design Alternatives. Environ. Sci. Technol. 2011, 45, 2457-2464. [CrossRef]

61. Pirasteh, G.; Saidur, R.; Rahman, S.M.A.; Rahim, N.A. A Review on Development of Solar Drying Applications. Renew. Sustain. Energy Rev. 2014, 31, 133-148. [CrossRef]

62. Ndukwu, M.C.; Bennamoun, L.; Abam, F.I.; Eke, A.B.; Ukoha, D. Energy and Exergy Analysis of a Solar Dryer Integrated with Sodium Sulfate Decahydrate and Sodium Chloride as Thermal Storage Medium. Renew. Energy 2017, 113, 1182-1192. [CrossRef]

63. Baral, S.; Kim, D.; Yun, E.; Kim, K.C. Experimental and Thermoeconomic Analysis of Small-Scale Solar Organic Rankine Cycle (SORC) System. Entropy 2015, 17, 2039-2061. [CrossRef]

64. Corona, B.; San Miguel, G.; Cerrajero, E. Life Cycle Assessment of Concentrated Solar Power (CSP) and the Influence of Hybridising with Natural Gas. Int. J. Life Cycle Assess. 2014, 19, 1264-1275. [CrossRef] 